\title{
Hydrogenative-PHIP polarized metabolites for biological studies
}

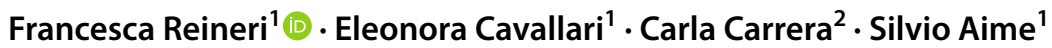

Received: 7 August 2020 / Revised: 9 December 2020 / Accepted: 18 December 2020 / Published online: 2 February 2021

(c) The Author(s) 2021

\begin{abstract}
ParaHydrogen induced polarization (PHIP) is an efficient and cost-effective hyperpolarization method, but its application to biological investigations has been hampered, so far, due to chemical challenges. PHIP is obtained by means of the addition of hydrogen, enriched in the para-spin isomer, to an unsaturated substrate. Both hydrogen atoms must be transferred to the same substrate, in a pairwise manner, by a suitable hydrogenation catalyst; therefore, a de-hydrogenated precursor of the target molecule is necessary. This has strongly limited the number of parahydrogen polarized substrates. The non-hydrogenative approach brilliantly circumvents this central issue, but has not been translated to in-vivo yet. Recent advancements in hydrogenative PHIP (h-PHIP) considerably widened the possibility to hyperpolarize metabolites and, in this review, we will focus on substrates that have been obtained by means of this method and used in vivo. Attention will also be paid to the requirements that must be met and on the issues that have still to be tackled to obtain further improvements and to push PHIP substrates in biological applications.
\end{abstract}

Keywords Hyperpolarization $\cdot$ Metabolism $\cdot$ Para-hydrogen $\cdot$ NMR

\section{Introduction}

Hyperpolarization techniques allow to increase the sensitivity of Nuclear Magnetic Resonance (NMR) based techniques (MRS and MRI) by orders of magnitude [1,2] and their application to biological systems opened new perspectives in the field of diagnostics [3, 4].

ParaHydrogen induced polarization (PHIP) was the first in vivo translated hyperpolarization technology and, in these first studies, hyperpolarized molecules were used as angiographic tracers $[5,6]$ outlining the advantage that the ${ }^{13} \mathrm{C}$ images of the injected hyperpolarized probes can be obtained within few tens of seconds after injection.

Soon after that, thanks to the set-up of dissolutiondynamic nuclear polarization (d-DNP) [2, 7], it was clear that the development of hyperpolarization techniques offer the possibility of gaining information about the real-time in vivo kinetics of the metabolic transformations [8] involving

Francesca Reineri

francesca.reineri@unito.it

1 Department of Molecular Biotechnology and Health Sciences, University of Torino, Via Nizza 52, Turin, Italy

2 Institute of Biostructures and Bioimaging, National Research Council, Via Nizza 52, Turin, Italy injected hyperpolarized substrates. Metabolic studies enabled by d-DNP become possible, in the clinics, due to significant investments by the stakeholders in this technology.

While, in principle, d-DNP can be applied to any substrate, some requirements must be met to allow hyperpolarization such as the formation of a glassy solid solution of the substrate and the free electron radical. Although significant technological advancements have been made to avoid the consumption of cryogenic fluids [9] and to obtain solutions of HP products ready for in-human use [10], the high costs and the complexity associated with d-DNP technology, combined with relatively low production rate, may represent a limitation to the adoption of this methodology.

Approaches exploiting ParaHydrogen induced polarization (PHIP) [11-15] could be attractive alternatives because of their markedly lower costs and instrumentation demands associated to much higher hyperpolarization rates (minutes to seconds, that, in some cases, allow a continuous agent production) [16-18].

Hydrogenative PHIP (h-PHIP) results from the addition of hydrogen, enriched in the para-isomer, to unsaturated substrates, catalyzed by organometallic complexes (Fig. 1). Therefore, h-PHIP polarized molecules contain two protons, that derive from the pairwise addition of hydrogen to the unsaturated precursor. This clearly represents a strong limitation to the PHIP polarizable substrates. In this context, 


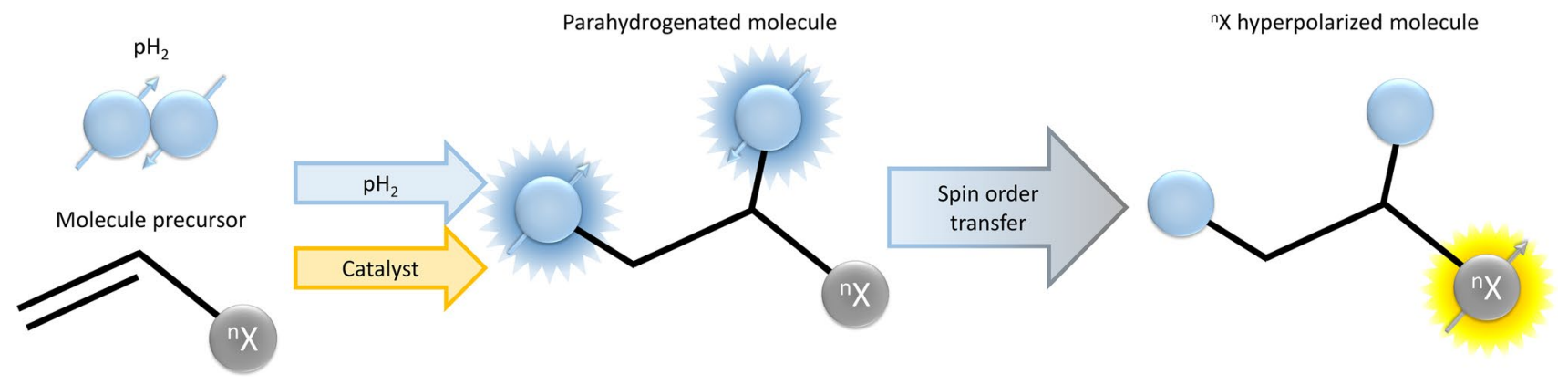

Fig. 1 Scheme representing hydrogenative-PHIP (h-PHIP). ${ }^{n} \mathrm{X}$ is the hyperpolarized heteroatom (usually a ${ }^{13} \mathrm{C}$ spin). In the first step, the unsaturated precursor of the target product is hydrogenated, using parahydrogen and an hydrogenation catalyst. Then, parahydrogen

the introduction of non-hydrogenative PHIP, named Signal Amplification by Reversible Exchange (SABRE), brilliantly circumvented this central issue [19]. This hyperpolarization method is based on the reversible formation of a ternary adduct between the target molecule, parahydrogen and an Iridium complex [20]. The hyperpolarization level gained on the products of SABRE depends on the exchange kinetics of the adduct and is a function of several experimental conditions, such as hydrogen pressure, use of co-solvents and strength of the magnetic field at which the process is carried out $[21,22]$. More recent studies about pyruvate hyperpolarization using SABRE [23] are paving the way to the in vivo application of this powerful and versatile technique [24].

Another significant feature of PHIP polarized materials is given by the attainment of hyperpolarized coherences on protons, that can be detected using dedicated pulse sequences such as the OPSY [25] introduced by Duckett et al. Acquisition of hyperpolarized proton signals would be a huge advantage for MRI applications and, in particular, for translation to the clinics, because heteronuclear coils are not usually implemented on clinical MRI scanners. Nevertheless the relaxation rate of ${ }^{1} \mathrm{H}$ signals remains a major issue, at least in conditions that are compatible with in-vivo applications (i.e., aqueous solutions of biocompatible molecules, containing oxygen). Locking these hyperpolarized signals into singlet states [26-28] can be a promising way to overcome this hurdle [29, 30].

Many strategies have been introduced, in this research field, to improve the hyperpolarization efficiency, to widen the pool of available substrates and to tackle the more general issue of the limited lifetime of hyperpolarization. This review does not aim to provide an overview of all of them, for which other works have been published recently $[15,31]$, but it will be mainly focused on h-PHIP.

Nevertheless, the molecules that have been hyperpolarized by means of PHIP, with a biological application in mind, will be reported in the first part of the review. Only few of them have been used for investigations in cell cultures and spin order is transformed into heteronuclear polarization by means of spin order transfer (SOT). In this case, the heteroatom is situated only two and three bonds away from the parahydrogen protons

in vivo. Attention will be focused on those molecules and on the methods that made possible the biological application.

Some major issues have still to be solved, and namely the hyperpolarization level, the concentration of the substrates and bio-compatibility of the hyperpolarized solutions. The routes that can be pursued, to tackle these main hurdles and push PHIP substrates in biological studies will be described.

\section{PHIP polarized molecules for biological studies}

During two decades, many biologically significant molecules, some of which are metabolites, their mimics, nutrients and drugs, have been hyperpolarized by means of parahydrogen based methods. Many of these substrates have been reported in Table 1, together with some of the features that are relevant for the biological studies, which are: (i) the solvent in which the final HP product is obtained; (ii) the concentration of the HP agent; (iii) the hyperpolarization level on protons and/or on carbon signals.

Among those, attention must be paid to that an aqueous solution, suitable for in vivo administration through intra-venous bolus injection, is obtained. In general, in the development of a hyperpolarized probe, the toxicity of the substrate and the $T_{1}$ relaxation of the HP signal play a central role. When PHIP polarization is considered, the solution in which the HP product is obtained becomes a central issue and carrying out the hyperpolarization step in an organic solvent becomes, often, unpractical. Unfortunately, the catalysts usually employed for the parahydrogen hyperpolarization are more active in organic solvents and most of the highest hyperpolarization levels [21] have been obtained using methanol or acetone (see Table 1).

The requirements about the purity and the sterility [10] of the solutions become much stringent if in-human applications are pursued. Albeit the clinical translation does not 
Table 1 PHIP polarized substrates for biological purposes. Some of these molecules have been hyperpolarized using different PHIP based methods. In these cases, they are listed in chronological order

\begin{tabular}{|c|c|c|c|c|c|c|c|}
\hline Molecule & $\mathrm{pH}_{2}$ & Solvent & [HPmolecule] & $\begin{array}{l}\text { Catalyst and HP } \\
\text { method }\end{array}$ & ${ }^{1} \mathrm{H} \mathrm{HP}$ & ${ }^{13} \mathrm{C} \mathrm{HP}$ & References \\
\hline \multicolumn{8}{|l|}{ Metabolites } \\
\hline Acetate & $92 \%$ & $\mathrm{D}_{2} \mathrm{O}$ & $75 \mathrm{mM}$ & $\begin{array}{l}\text { Rh } \\
\text { PHIP-SAH }\end{array}$ & & Yes, n.d & {$[32]$} \\
\hline \multirow[t]{3}{*}{$1-{ }^{13} \mathrm{C}$-acetate } & - & $\mathrm{CD}_{2} \mathrm{Cl}_{2}$ & $50 \mathrm{mM}$ & $\begin{array}{l}\text { Ir } \\
\text { SABRE-RELAY }\end{array}$ & - & 48 fold@9.4 T & {$[33]$} \\
\hline & $80 \%$ & $\begin{array}{c}\text { Methanol- } \mathrm{d}_{4} / \\
\text { ethanol- } \mathrm{d}_{6}\end{array}$ & $30-40 \mathrm{mM}$ & $\begin{array}{l}\text { Ir } \\
\text { SABRE }\end{array}$ & - & 108 fold@9.4 T & {$[34]$} \\
\hline & $92 \%$ & Methanol-d4/D2O & $0.9 \mathrm{mM}$ & $\begin{array}{l}\text { Rh } \\
\text { PHIP-SAH }\end{array}$ & & $19.3 \%$ & {$[35]$} \\
\hline $\begin{array}{l}\text { Acetate- } \mathrm{d}_{3} \\
1-{ }^{13} \mathrm{C} \text {-acetate- } \mathrm{d}_{3}\end{array}$ & $92 \%$ & $\begin{array}{l}\text { Acetone- } \mathrm{d}_{6} / \mathrm{D}_{2} \mathrm{O} \text { or } \\
\text { Methanol- } \mathrm{d}_{4} / \mathrm{D}_{2} \mathrm{O}\end{array}$ & $0.5 \mathrm{mM}$ & $\begin{array}{l}\text { Rh } \\
\text { PHIP-SAH }\end{array}$ & & $3.6 \%$ & {$[36]$} \\
\hline $1-{ }^{13} \mathrm{C}$-fumarate & $86 \%$ & $\mathrm{D}_{2} \mathrm{O}$ & $45 \mathrm{mM}$ & $\begin{array}{l}\text { Ru (water soluble) } \\
\text { h-PHIP }\end{array}$ & - & $24 \% @ 14.1 \mathrm{~T}$ & {$[37]$} \\
\hline $1-{ }^{13} \mathrm{C}$-lactate & $92 \%$ & $\mathrm{H}_{2} \mathrm{O}$ & $40-60 \mathrm{mM}$ & $\begin{array}{l}\text { Rh } \\
\text { PHIP-SAH }\end{array}$ & Yes & $2.9 \% @ 14.1 \mathrm{~T}$ & {$[38]$} \\
\hline $\begin{array}{l}1-{ }^{13} \mathrm{C}-\text { phospholac- } \\
\text { tate- } \mathrm{d}_{2}\end{array}$ & $90 \%$ & $\mathrm{D}_{2} \mathrm{O}$ & $25 \mathrm{mM}$ & $\begin{array}{l}\text { Rh (water soluble) } \\
\text { h-PHIP }\end{array}$ & - & $15 \% @ 47.5 \mathrm{mT}$ & $\begin{array}{l}{[39]} \\
{[40]}\end{array}$ \\
\hline $1-{ }^{13} \mathrm{C}$-pyruvate & $92 \%$ & $\mathrm{H}_{2} \mathrm{O}$ & $30-40 \mathrm{mM}$ & $\begin{array}{l}\text { Rh } \\
\text { PHIP-SAH }\end{array}$ & n.d & $3.5 \% @ 14.1 \mathrm{~T}$ & {$[41,41]$} \\
\hline $1-{ }^{13} \mathrm{C}$-pyruvate & $92 \%$ & $\begin{array}{l}\text { Acetone- } \mathrm{d}_{6} / \text { Metha- } \\
\text { nol- } \mathrm{d}_{4} / \mathrm{D}_{2} \mathrm{O}\end{array}$ & $0.75 \mathrm{mM}$ & $\begin{array}{l}\text { Rh } \\
\text { PHIP-SAH }\end{array}$ & & $3.4 \%$ & {$[36]$} \\
\hline $\begin{array}{l}1-{ }^{13} \mathrm{C} \text {-pyruvate } \\
2-{ }^{13} \mathrm{C} \text {-pyruvate }\end{array}$ & $93 \%$ & Methanol- $\mathrm{d}_{4}$ & $25-30 \mathrm{mM}$ & $\begin{array}{l}\text { Ir } \\
\text { SABRE }\end{array}$ & - & $\begin{array}{l}1 \% @ 9.4 \mathrm{~T} \\
0.6 \% @ 9.4 \mathrm{~T}\end{array}$ & [23] \\
\hline $1-{ }^{13} \mathrm{C}$-pyruvate & - & $\mathrm{CD}_{2} \mathrm{Cl}_{2}$ & $50 \mathrm{mM}$ & $\begin{array}{l}\text { Ir } \\
\text { SABRE-RELAY }\end{array}$ & - & $\begin{array}{l}0.039 \% * @ 9.4 \mathrm{~T} \\
\text { (48 fold) }\end{array}$ & [33] \\
\hline $1,2-{ }^{13} \mathrm{C}_{2}$-pyruvate & $99 \%$ & Methanol- $\mathrm{d}_{4}$ & $30 \mathrm{mM}$ & $\begin{array}{l}\text { Ir } \\
\text { SABRE }\end{array}$ & Yes & $\begin{array}{r}1.7 \% @ 9.4 \mathrm{~T}(\mathrm{C} 1 \\
\text { and } \mathrm{C} 2 \text { average })\end{array}$ & [43] \\
\hline $1,2-{ }^{13} \mathrm{C}_{2}$-pyruvate & $93 \%$ & Methanol- $\mathrm{d}_{4}$ & $25-30 \mathrm{mM}$ & $\begin{array}{l}\text { Ir } \\
\text { SABRE }\end{array}$ & - & $\begin{array}{l}1.8 \%(\mathrm{C} 1) \\
1.6 \%(\mathrm{C} 2) @ 9.4 \mathrm{~T}\end{array}$ & {$[23]$} \\
\hline $1,2-{ }^{13} \mathrm{C}_{2}$-pyruvate & $93 \%$ & $\begin{array}{l}\mathrm{D}_{2} \mathrm{O} / \text { Ethanol- } \mathrm{d}_{6} \\
\quad(70: 30)\end{array}$ & $0.4 \mathrm{mM}$ & $\begin{array}{l}\text { Ir } \\
\text { SABRE }\end{array}$ & - & n.d. & [23] \\
\hline $1-{ }^{13} \mathrm{C}$-succinate- $\mathrm{d}_{2}$ & $90 \%$ & $\mathrm{D}_{2} \mathrm{O}$ & $30 \mathrm{mM}$ & $\begin{array}{l}\text { Rh (water soluble) } \\
\text { h-PHIP }\end{array}$ & - & $28 \% @ 47.5 \mathrm{mT}$ & [39] \\
\hline $1-{ }^{13} \mathrm{C}$-succinate- $\mathrm{d}_{2}$ & $90 \%$ & $\mathrm{H}_{2} \mathrm{O}$ & $5 \mathrm{mM}$ & $\begin{array}{l}\text { Rh (water soluble) } \\
\text { h-PHIP }\end{array}$ & & $11 \%$ & [44] \\
\hline Urea $-{ }^{13} \mathrm{C}$ & - & $\mathrm{CD}_{2} \mathrm{Cl}_{2}$ & $50 \mathrm{mM}$ & $\begin{array}{l}\text { Ir } \\
\text { SABRE-RELAY }\end{array}$ & - & $\begin{array}{l}0.15 \% * @ 9.4 \mathrm{~T} \\
\quad(182 \text { fold })\end{array}$ & [33] \\
\hline Urea $-{ }^{13} \mathrm{C}-{ }^{15} \mathrm{~N}_{2}$ & - & $\mathrm{CD}_{2} \mathrm{Cl}_{2}$ & $25 \mathrm{mM}$ & $\begin{array}{l}\text { Ir } \\
\text { SABRE-RELAY }\end{array}$ & - & $\begin{array}{l}0.33 \% * \text { on }{ }^{13} \mathrm{C} @ \\
9.4 \mathrm{~T} \\
\text { (408 fold) } \\
{ }^{15} \text { N HP yes, n.d }\end{array}$ & [33] \\
\hline \multicolumn{8}{|c|}{ Amino acids and their derivatives } \\
\hline $1-{ }^{13} \mathrm{C}$-glycine & $80 \%$ & $\mathrm{D}_{2} \mathrm{O}$ & $0.6 \mathrm{mM}$ & $\begin{array}{l}\text { NAC@Rh } \\
\text { h-PHIP }\end{array}$ & $1.14 \%$ & $\begin{array}{c}0.29 \% @ 7 \mathrm{~T}, \\
353 \mathrm{~K}\end{array}$ & [45] \\
\hline $1-{ }^{13} \mathrm{C}$-alanine & $80 \%$ & $\mathrm{D}_{2} \mathrm{O}$ & $0.6 \mathrm{mM}$ & $\begin{array}{l}\text { NAC@Rh } \\
\text { h-PHIP }\end{array}$ & $1.02 \%$ & $\begin{array}{c}0.25 \% @ 7 \mathrm{~T}, \\
353 \mathrm{~K}\end{array}$ & [45] \\
\hline $\begin{array}{l}N \text {-acetyl-AAs } \\
\quad \text { (Phenylalanine) }\end{array}$ & $50 \%$ & Methanol- $\mathrm{d}_{4}$ & $40 \mathrm{mM}$ & $\begin{array}{l}\text { Rh } \\
\text { h-PHIP }\end{array}$ & Yes & $\begin{array}{l}1.3 \% @ 11.7 \mathrm{~T}, \\
298 \mathrm{~K} \text { of fully } \\
\text { deuterated } \\
N \text {-acetyl-1- }{ }^{13} \mathrm{C}- \\
\text { phenylalanine }\end{array}$ & {$[46]$} \\
\hline $\begin{array}{l}N \text {-unprotected } \\
\text { AA derivatives } \\
\text { (esters) }\end{array}$ & $95 \%$ & $\mathrm{D}_{2} \mathrm{O}$ & $\begin{array}{c}2 \mathrm{mM} \text { approx. } \\
(5-10 \% \text { of } \\
25 \mathrm{mM})\end{array}$ & $\begin{array}{l}\text { Rh (water soluble) } \\
\text { h-PHIP }\end{array}$ & $\begin{array}{l}0.7 \% \text { Gly and Ala } \\
\text { deriv } \\
0.5 \% \text { Gln } \\
@ 14.1 \mathrm{~T}, 353 \mathrm{~K}\end{array}$ & $\begin{array}{l}\text { 4.4\% alanine deriv. } \\
\text { @ } 9.4 \mathrm{~T}\end{array}$ & [47] \\
\hline
\end{tabular}


Table 1 (continued)

\begin{tabular}{|c|c|c|c|c|c|c|c|}
\hline Molecule & $\mathrm{pH}_{2}$ & Solvent & [HPmolecule] & $\begin{array}{l}\text { Catalyst and HP } \\
\text { method }\end{array}$ & ${ }^{1} \mathrm{H}$ HP & ${ }^{13} \mathrm{C} \mathrm{HP}$ & References \\
\hline \multicolumn{8}{|l|}{ Nitrogenous bases } \\
\hline $\begin{array}{l}\text { Glycine-histidine- } \\
\text { phenylalanine }\end{array}$ & $50 \%$ & Methanol- $\mathrm{d}_{4}$ & $\sim 2 \mathrm{mM}$ & $\begin{array}{l}\text { Ir } \\
\text { SABRE }\end{array}$ & Yes, n.d & - & [48] \\
\hline $\begin{array}{l}\text { Adenine } \\
\text { Adenosine }\end{array}$ & $95 \%$ & Methanol- $\mathrm{d}_{4}$ & $10 \mathrm{mM}$ & $\begin{array}{l}\text { Ir } \\
\text { SABRE }\end{array}$ & $\begin{array}{l}\text { Yes,n.d. 0.4\% @ } \\
\text { 9.4 T }\end{array}$ & - & [16] \\
\hline Adenine & $80-90 \%$ & Methanol-d $\mathrm{d}_{4}$ & n.d & $\begin{array}{l}\text { Ir } \\
\text { SABRE-SHEAT }\end{array}$ & - & $\begin{array}{l}0.06 \% * * * 15 \mathrm{~N} @ \\
8.5 \mathrm{~T}\end{array}$ & [49] \\
\hline $\begin{array}{l}\text { Adenosine } \\
\text { 5'-triphosphate } \\
\text { (ATP) }\end{array}$ & - & $\mathrm{CD}_{2} \mathrm{Cl}_{2}$ & $50 \mathrm{mM}$ & $\begin{array}{l}\text { Ir } \\
\text { SABRE-RELAY }\end{array}$ & - & $\begin{array}{l}0.063 \% *, 0.042 \% * \\
0.026 \% * \text { on } \\
{ }^{31} \mathrm{P} @ 9.4 \mathrm{~T} \\
(48,32,20 \text { fold })\end{array}$ & {$[33]$} \\
\hline Purine & & Methanol- $\mathrm{d}_{4}$ & $100 \mathrm{mM}$ & $\begin{array}{l}\text { Ir } \\
\text { SABRE }\end{array}$ & Yes, n.d & & [19] \\
\hline \multicolumn{8}{|l|}{ Nutrients } \\
\hline D-glucose & - & Acetone/ DMSO & $50 \mathrm{mM}$ & $\begin{array}{l}\text { Ir } \\
\text { SABRE-RELAY }\end{array}$ & $\begin{array}{l}0.13 \% * @ 9.4 \mathrm{~T} \\
\quad(40 \text { fold })\end{array}$ & - & {$[33]$} \\
\hline D-GLUCOSE- ${ }^{13} \mathrm{C}_{6}$ & - & $\mathrm{CD}_{2} \mathrm{Cl}_{2}$ & $50 \mathrm{mM}$ & $\begin{array}{l}\text { Ir } \\
\text { SABRE-RELAY }\end{array}$ & - & n.d & [33] \\
\hline $\begin{array}{l}\text { D-glucose- }{ }^{13} \mathrm{C}_{6} \\
\text { Fructose }-{ }^{13} \mathrm{C}_{6}-\mathrm{d}_{7}\end{array}$ & $99 \%$ & $\mathrm{CD}_{2} \mathrm{Cl}_{2} / \mathrm{DMF}$ & $20 \mathrm{mM}$ & $\begin{array}{l}\text { Ir } \\
\text { SABRE-RELAY }\end{array}$ & - & $\begin{array}{l}1.1 \%{ }^{13} \mathrm{C} @ 1 \mathrm{~T} \\
0.2 \%{ }^{13} \mathrm{C} @ 9.4 \mathrm{~T}\end{array}$ & {$[50]$} \\
\hline $\begin{array}{r}\text { Nicotinic acid } \\
\quad\left(\text { vitamin } B_{3}\right)\end{array}$ & - & Methanol- $\mathrm{d}_{4}$ & $40 \mathrm{mM}$ & $\begin{array}{l}\text { Ir } \\
\text { SABRE }\end{array}$ & $\begin{array}{l}2.6 \% * / \text { total }{ }^{1} \mathrm{H} \\
\quad \text { signal @9.4 T } \\
\text { (800 fold) }\end{array}$ & - & {$[51]$} \\
\hline Nicotinamide & $50 \%$ & Methanol-d $\mathrm{d}_{4}$ & n.d & $\begin{array}{l}\text { Ir } \\
\text { SABRE-SHEAT }\end{array}$ & - & $3.4 \%{ }^{15} \mathrm{~N} @ 8.5 \mathrm{~T}$ & [49] \\
\hline Nicotinamide- $\mathrm{d}_{2}$ & - & $\begin{array}{l}\text { Methanol-d } \mathrm{d}_{4} \\
\text { Ethanol- } \mathrm{d}_{6}\end{array}$ & $20 \mathrm{mM}$ & $\begin{array}{l}\text { Ir } \\
\text { SABRE }\end{array}$ & $\begin{array}{l}4.1 \% * * \\
2.1 \% * *\end{array}$ & - & {$[21]$} \\
\hline \multicolumn{8}{|l|}{ Drugs } \\
\hline $\begin{array}{l}\text { Alectinib (poten- } \\
\text { tial chemotera- } \\
\text { peutic) }\end{array}$ & $80-90 \%$ & Methanol- $\mathrm{d}_{4}$ & n.d & $\begin{array}{l}\text { Ir } \\
\text { SABRE-SHEAT }\end{array}$ & - & $\begin{array}{l}1.5 \% \text { on }{ }^{15} \mathrm{~N} \\
@ 8.5 \mathrm{~T}\end{array}$ & [49] \\
\hline $\begin{array}{c}\text { CHCA (chem- } \\
\text { oterapeutic) }\end{array}$ & $80-90 \%$ & Methanol-d $\mathrm{d}_{4}$ & n.d & $\begin{array}{l}\text { Ir } \\
\text { SABRE-SHEAT }\end{array}$ & - & $\begin{array}{l}1.1 \% \text { on }^{15} \mathrm{~N} @ \\
8.5 \mathrm{~T}\end{array}$ & [49] \\
\hline $\begin{array}{l}\text { Isoniazid (antitu- } \\
\text { bercolosis) }\end{array}$ & $92.5 \%$ & Methanol- $\mathrm{d}_{4}$ & $4 \mathrm{mM}$ & $\begin{array}{l}\text { Ir } \\
\text { SABRE }\end{array}$ & $\begin{array}{c}8 \% @ 16.4 \mathrm{~T}, \\
319 \mathrm{~K}\end{array}$ & - & {$[52]$} \\
\hline $\begin{array}{l}\text { Metronidazole } \\
\text { (antibiotic) }\end{array}$ & $75-85 \%$ & Methanol-d $\mathrm{d}_{4}$ & $20 \mathrm{mM}$ & $\begin{array}{l}\text { Ir } \\
\text { SABRE-SHEAT }\end{array}$ & - & $\begin{array}{r}34 \% \text { on }{ }^{15} \mathrm{~N} @ \\
9.4 \mathrm{~T}, 300 \mathrm{~K}\end{array}$ & {$[49,53]$} \\
\hline $\begin{array}{l}\text { PET tracers } \\
O-\left(2-\left[{ }^{18} \mathrm{~F}\right]\right. \\
\text { fluoroethyl)-1- } \\
\text { tyrosine }\left(\left[{ }^{18} \mathrm{~F}\right]\right. \\
\text { FET }) \\
{\left[{ }^{18} \mathrm{~F}\right] \text { fallypride }} \\
\left(\left[{ }^{18} \mathrm{~F}\right] \mathrm{FP}\right)\end{array}$ & $92 \%$ & $\begin{array}{l}\text { Acetone- } \mathrm{d}_{6} / \mathrm{D}_{2} \mathrm{O} \\
\text { and ethanol- } \mathrm{d}_{6} / \\
\mathrm{D}_{2} \mathrm{O} \\
\text { MeOD-d4 }\end{array}$ & $\begin{array}{l}12 \mathrm{mM}(12 \% \text { of } \\
100 \mathrm{mM}) \\
8 \mathrm{mM}\end{array}$ & $\begin{array}{l}\mathrm{Rh} \\
\mathrm{h}-\mathrm{PHIP}\end{array}$ & $\begin{array}{l}4.5 \% * @ 7 \mathrm{~T} \\
3.5 \% * \\
\text { @7 T, 333 K }\end{array}$ & $\begin{array}{l}\text { 4-7.4\%@7 T, } \\
333 \mathrm{~K} \\
3.1 \% @ 7 \mathrm{~T}, 333 \mathrm{~K}\end{array}$ & {$[54]$} \\
\hline $\begin{array}{l}\text { Pyrazinamide } \\
\text { (antituberco- } \\
\text { losis) }\end{array}$ & $92.5 \%$ & Methanol-d $\mathrm{d}_{4}$ & $4 \mathrm{mM}$ & $\begin{array}{l}\text { Ir } \\
\text { SABRE }\end{array}$ & $\begin{array}{c}8 \% @ 16.4 \mathrm{~T}, \\
319 \mathrm{~K}\end{array}$ & - & {$[52]$} \\
\hline
\end{tabular}

*To facilitate comparison between the polarizations reported in this table, the $\mathrm{P} \%$ was calculated as the ratio of the reported signal enhancement with respect to the maximum signal enhancement at the experimental used magnetic field and temperature

**Maximum polarization on one of the bis-deuterated analogs

***Enhancement averaged over all ${ }^{15} \mathrm{~N}$ sites 
seem close, at present, for PHIP polarized substrates, these aspects must be kept in mind during the development of these agents.

Nevertheless, in vivo pre-clinical studies are possible provided that physiologically compatible solutions are obtained, at physiological $\mathrm{pH}$ (6.5-7.4) and osmolarity in the range of 250-500 mOsm/L (physiological osmolarity $290 \mathrm{mOsm} / \mathrm{L}$ ). Cytotoxicity studies can also be carried out to assess the biocompatibility of the substances. These requirements have been met for some of the PHIP polarized substrates, as will be detailed in a following section. In the end, it can also be reminded that the first in-vivo studies employing PHIP polarized substrates made use of a toxic molecule [5, 6] which was employed to obtain angiographic ${ }^{13} \mathrm{C}$ images.

The high amount of the agents used for in-vivo experiments must also be considered, in fact, the concentration of HP pyruvate used for pre-clinical studies is a few tens of millimolar $(80 \mathrm{mM})$ and ranges from 80 to $250 \mathrm{mM}[55,56]$ in humans. The biocompatibility of the substrate can become an issue, at this dose.

Furthermore, the hyperpolarization carried out by means of PHIP must be able to provide doses of the HP agent at those concentrations (or higher) in few seconds, to minimize hyperpolarization decay due to relaxation.

Considering all these features, i.e., the biocompatibility of the solution of the HP agent, the high concentration and the polarization level of the probe, a few of the PHIP polarized substrates that are listed in Table 1 become closer to the biological applications than other. These substrates, together with the h-PHIP based methods used for their hyperpolarization, will be described in more details in the following paragraphs.

\section{h-PHIP polarized metabolites}

\section{$\left[1-{ }^{13} \mathrm{C}\right]$ pyruvate, $\left[1-{ }^{13} \mathrm{C}\right]$ lactate and $\left[1-{ }^{13} \mathrm{C}\right]$ acetate}

Among all the hyperpolarized bio-molecules, $\left[1-{ }^{13} \mathrm{C}\right]$ pyruvate is, by far, the most widely investigated metabolite.
Pyruvate is at the intersection of pathways important for glucose and energy homeostasis. Thus the information that may be gained about pyruvate metabolism is crucial in tumours' characterization as well other pathologies. The translational path of d-DNP methodology to the clinics has yielded very promising results on advanced trials with $\left[1-{ }^{13} \mathrm{C}\right]$ pyruvate metabolism in prostate [57] and breast cancer [56]. Moreover, important studies dealing with the characterization of energy metabolism in human brain tumors [58] and in the investigation of heart metabolism [59] have been published.

Hyperpolarized $\left[1-{ }^{13} \mathrm{C}\right]$ lactate $[59,60]$ and $\left[1-{ }^{13} \mathrm{C}\right]$ acetate [61] have also been the subject of in vivo metabolic investigations in rodents (mice or rats), using d-DNP polarized substrates.

Since de-hydrogenated precursors of these molecules were not available, their hyperpolarization by direct incorporation of para-enriched hydrogen was precluded and the d-DNP route was considered as the only viable possibility.

The Side Arm Hydrogenation (SAH) strategy (Fig. 2) overcomes this issue by esterification of the carboxylate with an unsaturated alcohol (the side-arm) [32].

The unsaturated moiety in the added ester functionality is hydrogenated with parahydrogen in an organic, hydrophobic solvent, i.e., chloroform, to pursue an efficient hydrogenation. Then one proceeds with the hydrolysis of the ester and a phase separation step of the now hyperpolarized sodium salt of the carboxylate containing compound.

Parahydrogen spin order is transferred to ${ }^{13} \mathrm{C}$ spin polarization through small J-couplings $(<1 \mathrm{~Hz})$. In the reported works, this has been achieved by means of the non-selective polarization transfer procedure named magnetic field cycle (MFC) [62]. Alternative methods for the transformation of parahydrogen spin order into heteronuclear magnetization, through the application of RF pulses, have also been proposed and will be described later.

The hydrolysis reaction is carried out by injecting a aqueous heated solution of sodium hydroxide into the organic solvent containing the hydrogenated ester and the hydrogenation catalyst to obtain a two phase system, where the aqueous phase contains the hyperpolarized sodium salt. By

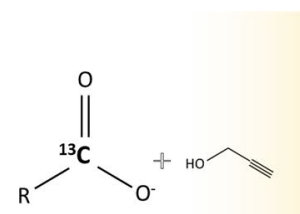

(1)

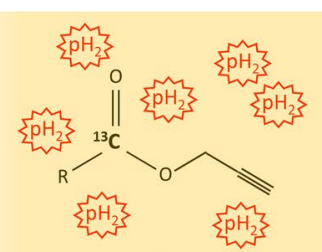

(2)

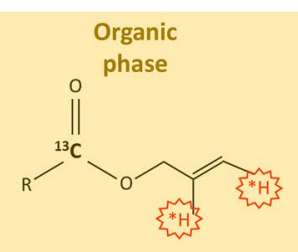

(3)

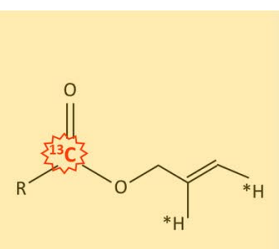

(4)

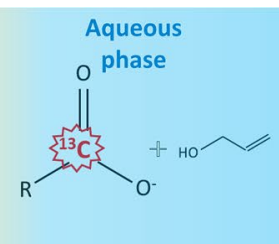

(5)
Fig. 2 Scheme reporting the key steps of the PHIP-SAH procedure: (1) functionalization of the target molecule with an unsaturated alcoholic group (propargyl or vinyl alcohol); (2) and (3) hydrogenation using parahydrogen of the unsaturated moiety; (4) polarization transfer to the ${ }^{13} \mathrm{C}$ carboxylate spin by means of magnetic field cycle (MFC); (5) hydrolysis and phase transfer of the sodium salt from the organic to the aqueous phase 
this procedure, almost $99 \%$ of the metal containing catalyst remains in the organic phase [31].

In principle, this procedure can be applied to any molecule containing a carboxylic group and it was used to obtain aqueous solutions of ${ }^{13} \mathrm{C}$ hyperpolarized $\left[1-{ }^{13} \mathrm{C}\right]$ pyruvate, $\left[1-{ }^{13} \mathrm{C}\right]$ acetate $[32,32]$ and $\mathrm{L}-\left[1-{ }^{13} \mathrm{C}\right]$ lactate [64], suitable for biological applications. The in vitro transformation of hyperpolarized $\mathrm{L}-\left[1-{ }^{13} \mathrm{C}\right]$ lactate into $\left[1-{ }^{13} \mathrm{C}\right]$ pyruvate has been tested in a buffered solution of lactate dehydrogenase (LDH), coenzymes and sodium pyruvate and in a suspension of breast cancer (TS/A) lysed cells.

Propargyl esters are commonly used in this process, but esters from other unsaturated alcohols have been tested (Fig. 3). For instance, vinyl and allyl esters have also been successfully tested $[63,64]$ (Salnikov et al. 2019). However, the vinyl ester lactate derivative has led to a lower ${ }^{13} \mathrm{C}$ polarization than the propargylic one, under the same hydrogenation and polarization transfer condition, as reported in Table 2 [64]. This is probably due to the less efficient hydrogenation of the double bond.

The hyperpolarized ester of pyruvate, lactate and acetate created and studied so far using the PHIP-SAH procedure are presented in Table 2 .

\section{Metabolic studies and Bio-compatibility of PHIP-SAH hyperpolarized pyruvate}

Recently the first in vitro applications of PHIP-SAH hyperpolarized $\left[1-{ }^{13} \mathrm{C}\right]$ Pyruvate have been reported for assessing upregulated glycolysis in murine breast cancer cell lines (168FARN and 4T1) (Fig. 4) [65] as well as the probing of metabolism in different prostate cancer cells lines (DU145, PC3, and LnCap) [66]. In both studies, the metabolic results were well consistent with those of conventional biochemical investigations, thus showing that the method of hyperpolarization does not affect the metabolic pathways in the investigated cells.

Nevertheless, small amounts of organic solvent $(1.7 \pm 0.3 \mathrm{mM})$, alcohol derived from cleavage of the ester (allyl alcohol $1.8 \pm 0.4 \mathrm{mM}$ ) or metal catalyst $(0.7 \pm 0.1 \mu \mathrm{g})$ are present in the aqueous solution of the HP product.

In vitro cytotoxicity has been investigated [66] and the colorimetric viability assay based on the tetrazolium dye MTT (3-(4,5-dimethylthiazol-2-yl)-2,5-diphenyltetrazolium bromide) showed moderate cytotoxicity (on prostate cancer cells) of the aqueous solution after $24 \mathrm{~h}$ treatment. Carrying out the toxicity tests of each single unwanted component of the solution, it was found that the toxic effect is due to the presence of traces of the organic solvent, rather than of the alcohol derived from cleavage of the ester or of the metal catalyst $(0.7 \pm 0.1 \mu \mathrm{g})$.

An in vivo metabolic study has also been reported on transgenic mice [67] in which the transformation of pyruvate into lactate can be detected in different tissues (Fig. 5).

In conclusion, the reported in-cells and in vivo studies show that the polarization level and the concentration of the metabolites hyperpolarized by means of PHIP-SAH, although seeking for further improvements, are already sufficient for carrying out these metabolic investigations. The impurities still present in the water solution of the HP product do not interfere with metabolism in cells and are compatible with pre-clinical investigations in animal models of diseases, nevertheless advancements are necessary,
Fig. 3 Chemical structures of compounds that have been used in the PHIP-SAH procedure. a $\left[1-{ }^{13} \mathrm{C}\right]$ allyl pyruvate, $\mathbf{b}\left[1-{ }^{13} \mathrm{C}\right]$ allyl lactate, $\mathbf{c}\left[1-{ }^{13} \mathrm{C}\right]$ Ethyl Lactate, $\mathbf{d}\left[1-{ }^{13} \mathrm{C}\right]$ allyl acetate, $\mathbf{e}$ $\left[1-{ }^{13} \mathrm{C}\right]$ ethyl acetate
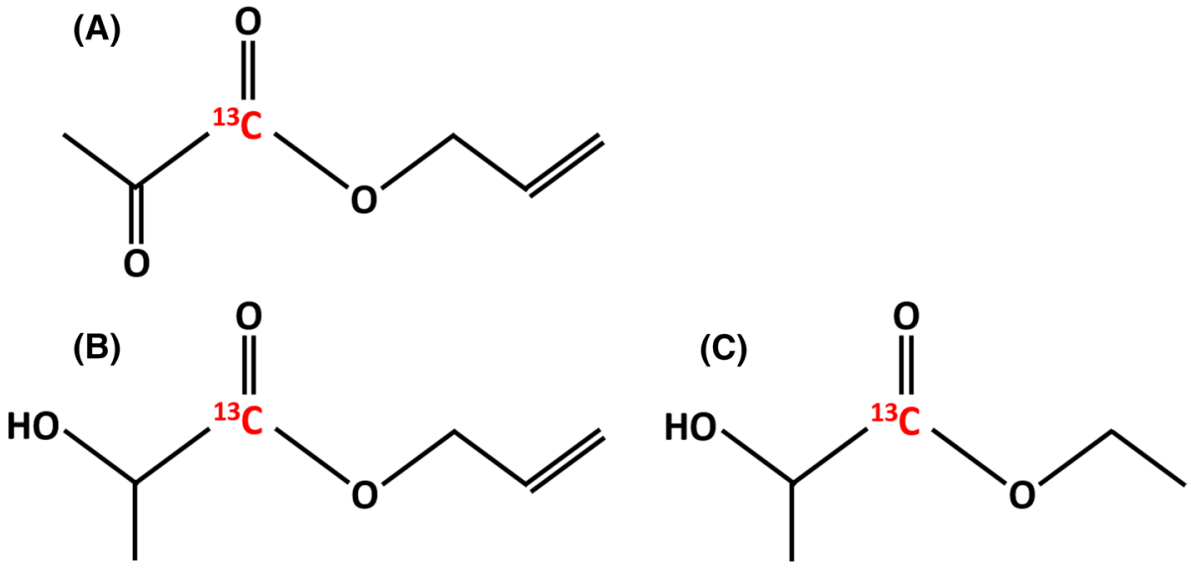

(D)

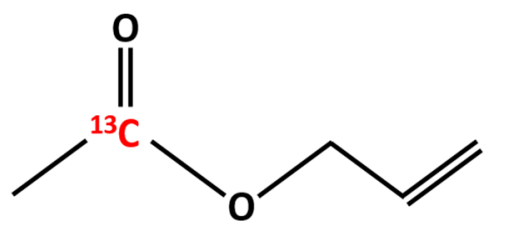

(E)

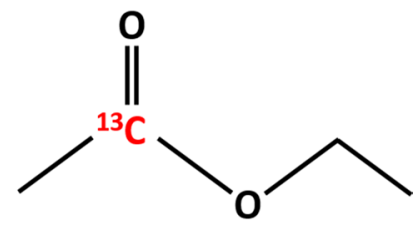


Table 2 PHIP-SAH polarized derivatives: ${ }^{13} \mathrm{C}$ polarization is reported together with the experimental conditions (solvents, catalyst, parahydrogen percentage) in which this polarization has been obtained

\begin{tabular}{|c|c|c|c|c|c|c|}
\hline HP agent & $\mathrm{pH}_{2}$ & Solvent & Catalyst & $\begin{array}{l}\text { Measured polariza- } \\
\text { tion \% (ester) }\end{array}$ & $\begin{array}{l}\text { Measured polarization } \\
\% \text { after cleavage }\end{array}$ & References \\
\hline$\left[1-{ }^{13} \mathrm{C}\right]$ allyl pyruvate & $86 \%$ & $\mathrm{CDCl}_{3}+$ Ethanol & {$[\mathrm{Rh}(\mathrm{COD})(\mathrm{dppb})] \mathrm{BF}_{4}$} & $6.2 \pm 0.3$ & $3.5 \pm 0.5$ & [111] \\
\hline$\left[1-{ }^{13} \mathrm{C}\right]$ allyl pyruvate & $85 \%$ & $\mathrm{CD}_{3} \mathrm{OD}$ & {$[\mathrm{Rh}(\mathrm{nbd})(\mathrm{dppb})] \mathrm{BF}_{4}$} & 5.4 & & [134] \\
\hline$\left[1-{ }^{13} \mathrm{C}\right]$ allyl pyruvate & $85 \%$ & $\mathrm{D}_{2} \mathrm{O}$ & $\begin{array}{l}{[\mathrm{Rh}-(\mathrm{nbd})} \\
\quad\left(\mathrm{Ph}\left(\left(\mathrm{CH}_{2}\right)_{3} \mathrm{SO}_{3^{-}}\right)\right. \\
\mathrm{P}-\left(\mathrm{CH}_{2}\right)_{4^{-}} \\
\left.\left.\quad \mathrm{PPh}\left(\left(\mathrm{CH}_{2}\right)_{3} \mathrm{SO}_{3^{-}}\right)\right)\right]-\mathrm{BF}_{4}\end{array}$ & 0.82 & & [134] \\
\hline$\left[1-{ }^{13} \mathrm{C}\right]$ ethyl pyruvate & $85 \%$ & $\mathrm{CD}_{3} \mathrm{OD}$ & {$[\mathrm{Rh}(\mathrm{nbd})(\mathrm{dppb})] \mathrm{BF}_{4}$} & 0.88 & & [134] \\
\hline$\left[1-{ }^{13} \mathrm{C}\right]$ propyl pyruvate & $85 \%$ & $\mathrm{CD}_{3} \mathrm{OD}$ & {$[\mathrm{Rh}(\mathrm{nbd})(\mathrm{dppb})] \mathrm{BF}_{4}$} & 0.49 & & [134] \\
\hline$\left[1-{ }^{13} \mathrm{C}\right]$ allyl lactate & $86 \%$ & $\mathrm{CDCl}_{3}$ & {$[\mathrm{Rh}(\mathrm{COD})(\mathrm{dppb})] B F_{4}$} & $4.5 \pm 0.5$ & $2.9 \pm 0.2$ & {$[64]$} \\
\hline$\left[1-{ }^{13} \mathrm{C}\right]$ ethyl lactate & $86 \%$ & $\mathrm{CDCl}_{3}$ & {$[\mathrm{Rh}(\mathrm{COD})(\mathrm{dppb})] B F_{4}$} & $2.0 \pm 0.1$ & & {$[64]$} \\
\hline$\left[1-{ }^{13} \mathrm{C}\right]$ allyl acetate & $50 \%$ & $\mathrm{CDCl}_{3}$ & {$[\mathrm{Rh}(\mathrm{COD})(\mathrm{dppb})] B F_{4}$} & 2.3 & & {$[62]$} \\
\hline$\left[1-{ }^{13} \mathrm{C}\right]$ ethyl acetate & $85 \%$ & $\mathrm{CD}_{3} \mathrm{OD}$ & {$[\mathrm{Rh}(\mathrm{COD})(\mathrm{dppb})] B F_{4}$} & 4.4 & & {$[134]$} \\
\hline$\left[1-{ }^{13} \mathrm{C}\right]$ ethyl acetate & $85 \%$ & $\mathrm{D}_{2} \mathrm{O}$ & $\begin{array}{l}{[\mathrm{Rh}-(\mathrm{nbd})} \\
\quad\left(\mathrm{Ph}\left(\left(\mathrm{CH}_{2}\right)_{3} \mathrm{SO}_{3^{-}}\right)\right. \\
\mathrm{P}-\left(\mathrm{CH}_{2}\right)_{4}^{-} \\
\left.\left.\quad \mathrm{PPh}\left(\left(\mathrm{CH}_{2}\right)_{3} \mathrm{SO}_{3^{-}}\right)\right)\right]-\mathrm{BF}_{4}\end{array}$ & 2.1 & & [134] \\
\hline$\left[1-{ }^{13}\right.$ C]propyl acetate & $85 \%$ & $\mathrm{CD}_{3} \mathrm{OD}$ & {$[\mathrm{Rh}(\mathrm{nbd})(\mathrm{dppb})] \mathrm{BF}_{4}$} & 0.35 & & [134] \\
\hline
\end{tabular}
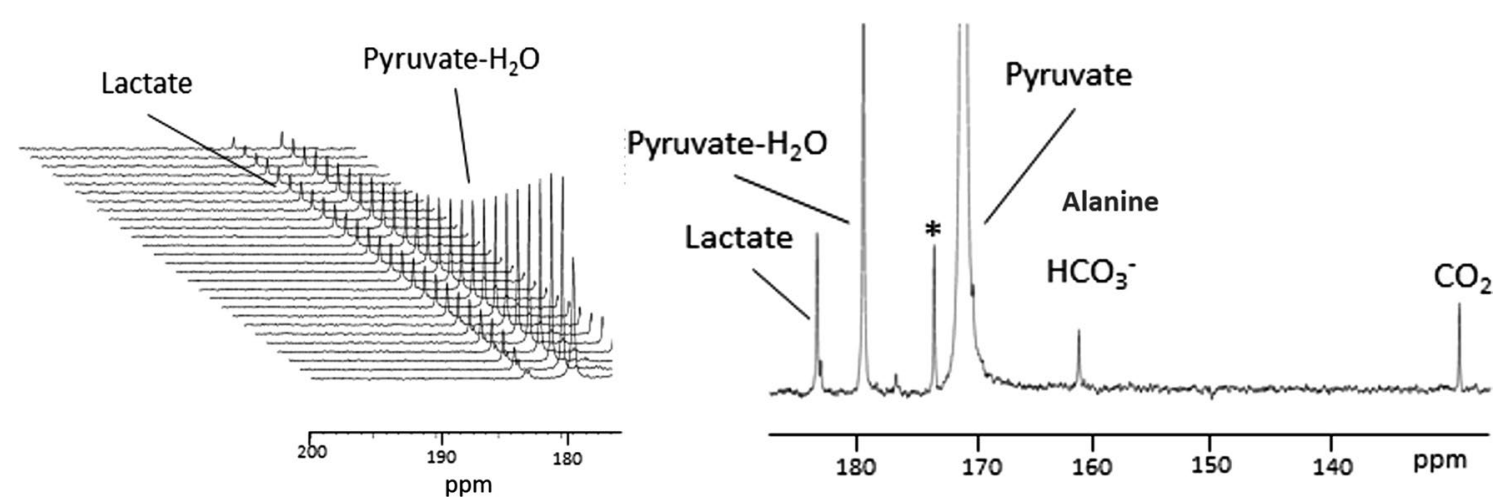

Fig. 4 (Left) Stacked plot of the successively acquired ${ }^{13} \mathrm{C}$ NMR spectra, following to the injection of HP $\left[1-{ }^{13} \mathrm{C}\right]$ pyruvate through a $168 \mathrm{FARN}$ cells suspension; right) one of the ${ }^{13} \mathrm{C}$ NMR spectra of the series [65]

concerning the purity of the product, in a perspective of inhuman applications. All these aspects will be discussed later.

\section{$\left[1-{ }^{13} \mathrm{C}\right]$ Fumarate}

Fumarate (trans-butenedioic acid) is a metabolite that cells convert into malate or succinate. The use of d-DNP hyperpolarized fumarate to report on fumarase activity was the subject of intense scrutiny $[68,69]$. That enzyme is responsible for the interconversion of fumarate and malate and is localized exclusively within the cells cytoplasm and mitochondria. Fumarate enters the cells through the sodium dependent dicarboxylate acid transporters and the fumarate-malate metabolic transformation is observed, using the
d-DNP hyperpolarized molecule, only in damaged cells, that are characterized by profoundly altered membranes. From this work it was realized that there was a good correlation between the rate of malate formation and the level of cell necrosis. Thus fumarate appears an excellent reporter on therapeutic treatments leading to tumor necrosis, i.e., of conditions in which the intracellular fumarase is allowed to interact with the administered hyperpolarized fumarate.

Besides tumors, the diagnostic potential of fumarate was also assessed in the case of acute kidney injury for its ability to distinguish between acute tubular necrosis (ATN) and glomerular-necrosis (GN) [69]. In fact a significant increase of the $\left[{ }^{13} \mathrm{C}\right]$ malate resonances was observed in the kidneys of mice with ATN (induced by Folic Acid treatment) at the 

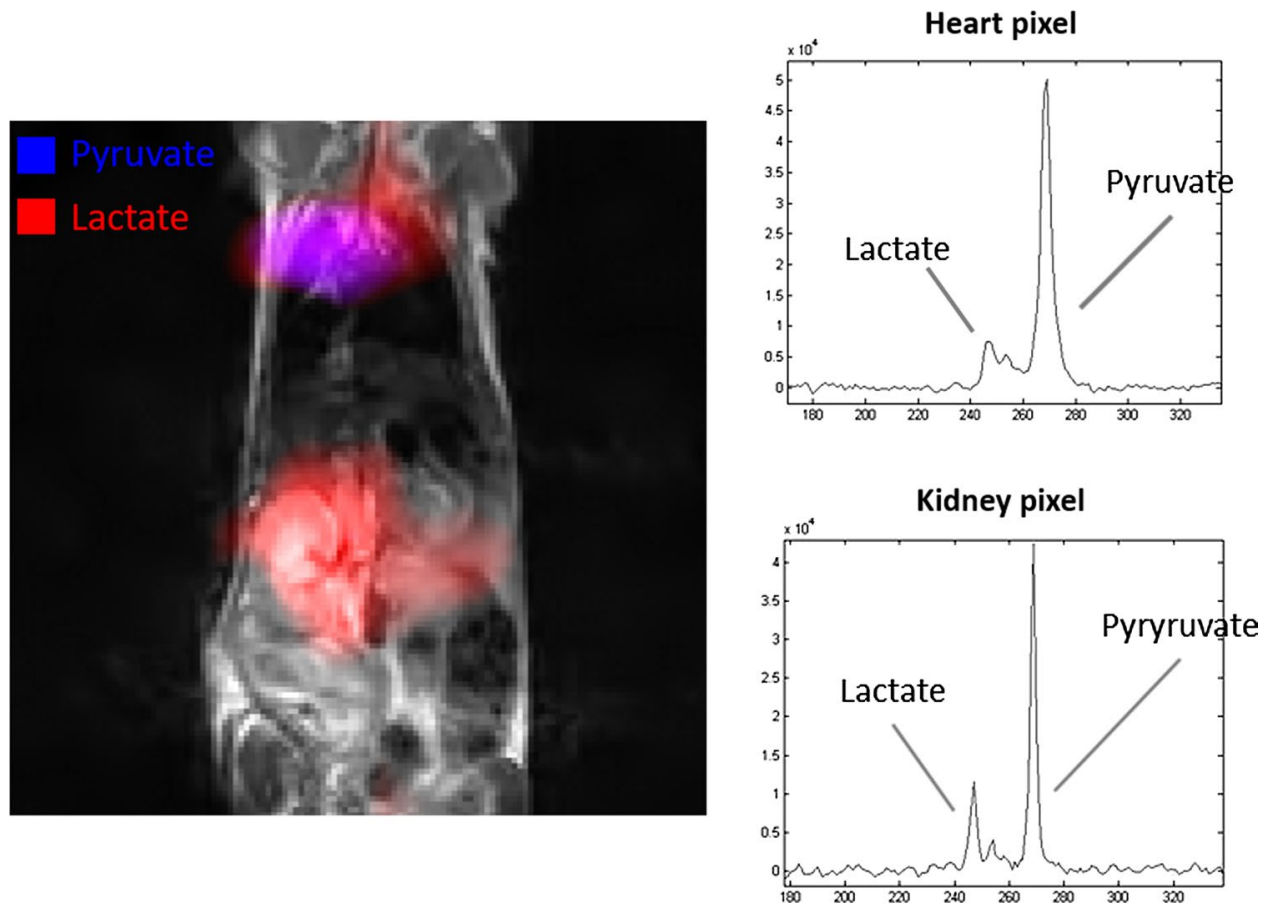

Fig. $5{ }^{13} \mathrm{C}$-chemical shift image reporting pyruvate and lactate distribution acquired on healthy living mouse (BALB/c). The ${ }^{13} \mathrm{C}-\mathrm{CSI}$ $20 \times 20$ pixels image was acquired using $1 \mathrm{~T}$ MRI (ASPECT $2 \mathrm{M}$ system) $15 \mathrm{~s}$ after injection of $170 \mu \mathrm{HP}\left[1-{ }^{13} \mathrm{C}\right]$ pyruvate solu-

early onset of the disease before histological changes were detectable. No such increase was observed in kidneys with acute GN.

Due to these reasons, parahydrogen hyperpolarization of fumarate is quite appealing for metabolic studies. The vast majority of the parahydrogenation reactions reported in the literature make use of rhodium based complex that leads to cis-hydrogenation of substrates. Using this catalyst, the acetylene dicarboxylate precursor readily forms maleate, i.e., the cis-isomer of the butanedioic acid. Since maleate is a toxic compound, in the context of PHIP applications, tion $(35 \mathrm{Mm})$. The spatial localization of each metabolite is shown upon overlapping the ${ }^{13} \mathrm{C}$-CSI results to the anatomical ${ }^{1} \mathrm{H}$-image $\left(T_{2}\right.$ weighted image). Each metabolite map is scaled individually and is displayed on blue (pyruvate) and red (lactate) colour scale

only complete hydrogenation to succinate leads to a useful metabolite.

It was shown, recently, that fumarate can be obtained from the pairwise hydrogenation of an acetylene dicarboxylate (ADC) precursor in water [70], using a ruthenium-based catalyst $\left.\left[\mathrm{RuCp} *(\mathrm{MeCN})_{3}\right] \mathrm{PF}_{6}\right]$ to achieve the necessary trans-hydrogenation (Fig. 6) [71, 72], with a minor formation of the fully hydrogenated succinate product.

Hydrogenation of ADC to fumarate, using para-hydrogen, does not lead to hyperpolarization, because the two alkenic hydrogen atoms are chemically and magnetically equivalent.<smiles>O=C(O)C#C[13C](=O)[O-]</smiles>

$\left[1-{ }^{13} \mathrm{C}\right]$ acetylenedicarboxylate<smiles>O=C([O-])C=CC(=O)O</smiles>

$\left[1-{ }^{13} \mathrm{C}\right]$ fumarate

Fig. 6 Reaction scheme showing the chemical addition of para-enriched hydrogen to an unsaturated $\left[1-{ }^{13} \mathrm{C}\right]$ acetylene dicarboxylate precursor, to yield $\left[1-{ }^{13} \mathrm{C}\right]$ fumarate 
This situation changes when the fumarate is ${ }^{13} \mathrm{C}$ enriched, either in one (C-1) or in two (C-1 and $\mathrm{C}-4)$ positions as the presence of different $\mathrm{J}_{\mathrm{CH}}$ couplings introduce magnetic asymmetry and consequently loss of the singlet state. Actually, as the two protons remain close to the magnetic equivalence, it was shown that an enhanced ${ }^{13} \mathrm{C}$ signal can be obtained by applying a specific pulse sequence such as $\mathrm{S} 2 \mathrm{hM}$ (singlet to heteronuclear magnetization) [73]. The reported experimental work-up relied on: (i) hydrogenation of disodium acetylene $\left[1-{ }^{13} \mathrm{C}\right]$ dicarboxylate with parahydrogen in the presence of the ruthenium catalyst at $50{ }^{\circ} \mathrm{C}$ in the NMR tube inside the magnet; (ii) application of the S2hM pulse sequence optimized for the J-couplings in fumarate and (iii) the ${ }^{13} \mathrm{C}$ acquisition. The applied pulse sequence led only to the enhancement of the central peak of the triplet pattern of the ${ }^{13} \mathrm{C}$ carboxylate resonance and ${ }^{13} \mathrm{C}$ polarization level was $1 \%$. This work reported that, in degassed conditions, ${ }^{1} \mathrm{H}-T_{1}$ of fumarate is $22.6 \pm 0.3 \mathrm{~s}$, but the ${ }^{1} \mathrm{H}$ singlet relaxation time $T_{\mathrm{s}}$ is longer (46 $\pm 7 \mathrm{~s}$ ), since the singlet state is immune to intra-pair ${ }^{1} \mathrm{H}-{ }^{1} \mathrm{H}$ dipolar relaxation. ${ }^{13} \mathrm{C}$ relaxation is dominated by the chemical shift anisotropy (CSA) mechanism and the relaxation rate is, therefore, inversely related to the magnetic field strength. A very interesting insight to prolong the lifetime of the hyperpolarized fumarate was suggested via the precipitation of fumarate as solid [74]. In the case of fumarate, this task is easily fulfilled by decreasing the $\mathrm{pH}$ as the formed fumaric acid is very poorly soluble in aqueous solutions. In principle this approach may pave the way to innovative routes for storing the hyperpolarization for long times, thanks to the extremely low $\mathrm{T}_{1}$ of solids.

The hyperpolarization of $\left[1-{ }^{13} \mathrm{C}\right]$ fumarate resonance was markedly enhanced using a magnetic field cycle (MFC) [75-77], instead of the rf pulses for spin order transfer (SOT), together with a more efficient hydrogenation method [37]. In fact, highly polarized $\left(24 \%{ }^{13} \mathrm{C}\right.$ polarization $)$ and concentrated (approx. $45 \mathrm{mM}$ ) fumarate solutions were obtained [37] thus showing the relevance of the hydrogenation conditions on the hyperpolarization level attainable using hydrogenative PHIP. The metabolic conversion of PHIP polarized fumarate into malate was reported (Fig. 7), using lysed cells, while it was not observed using intact cells.

\section{$\left[1-{ }^{13} \mathrm{C}\right]$ Succinate}

It was recognized relatively quickly that aqueous solutions of hyperpolarized succinate could be obtained directly through the addition of parahydrogen to the unsaturated precursors represented by acetylene dicarboxylate and fumarate [78, 79]. Figure 8 shows the hydrogenation reaction of $\left[1-{ }^{13} \mathrm{C}\right]$ acetylenedicarboxylate in water catalyzed by the watersoluble analog of the most widely applied PHIP catalyst, i.e., a rhodium(I) complex containing a chelating phosphine. The entire hyperpolarization procedure (hydrogenation and

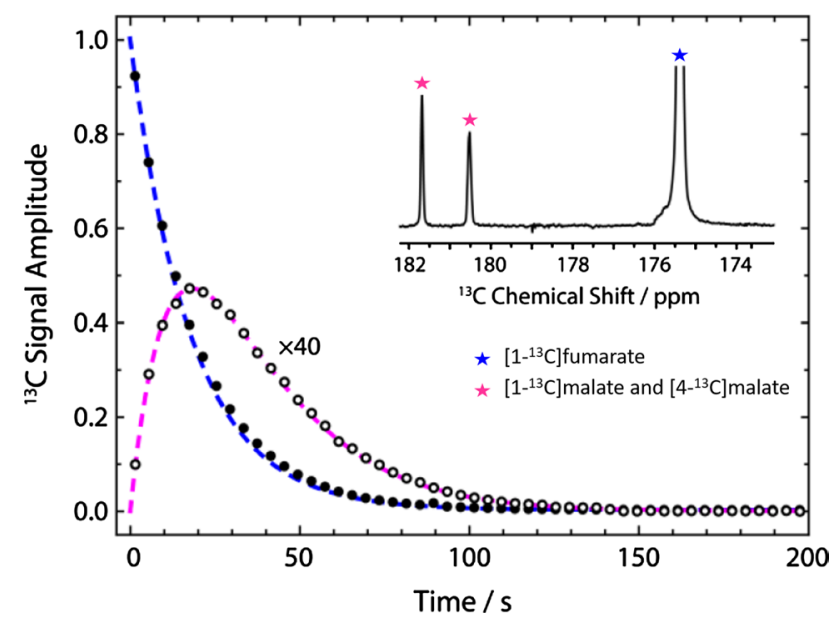

Fig. 7 Top: ${ }^{13} \mathrm{C}$ carboxylate resonances of fumarate (175.4 ppm) is well distinct from the corresponding resonances of malate $(\mathrm{C}-1$, 181.8 and C-4, $180.6 \mathrm{ppm})$. Bottom: flux of ${ }^{13} \mathrm{C}$ label between fumarate and malate in a suspension of lysed EL-4 tumour cells. The filled black dots represent integrals of $\left[1-{ }^{13} \mathrm{C}\right]$ fumarate and hollow black dots represent integrals of $\left[1-{ }^{13} \mathrm{C}\right]$ malate $+\left[4-{ }^{13} \mathrm{C}\right]$ malate signals

heteronuclear hyperpolarization) is conveniently carried out using a PHIP polarizer. Several of these polarizers have been constructed and will be described in another section of this review.

Succinate is involved in the tricarboxylic acid cycle (TCA) cycle, the pivot of cellular metabolism and of the production of energy; numerous diseases, such as cancer or neurological disorders, are correlated to dysfunctions of the TCA cycle. It is evident that being able to analyze these metabolic transformations by means of the hyperpolarization technique is of considerable interest in the diagnostic field. Unfortunately, the metabolic products of succinate cannot be observed using this hyperpolarized substrate maybe due to the slow rate of the transport across the cellular membrane. Nevertheless, it is the first metabolite that has been hyperpolarized by means of hydrogenative PHIP [78] and is still used as a standard compound for polarizer testing [40], tests of RF pulse sequences for spin order transfer [80] and to carry out in vivo imaging $[39,81]$.

Parahydrogen hyperpolarized $\left[1-{ }^{13} \mathrm{C}\right]$ succinate was obtained through the catalytic parahydrogenation of $\left[1-{ }^{13} \mathrm{C}\right]$ acetylenedicarboxylate [78] in water solution, using a prototype polarizer operating at few $\mathrm{mT}$. The parahydrogenation reaction was carried out in a so-called laminar flow reaction chamber [82, 83] and transfer of parahydrogen spin order to ${ }^{13} \mathrm{C}$ magnetization was obtained by means of the application of RF pulses. The HP contrast agent was injected in a rat and a ${ }^{13} \mathrm{C}$ MR image was acquired on a $1.5 \mathrm{~T}$ MR scanner, using a $\left[1-{ }^{13} \mathrm{C}\right]$ acetate phantom as reference. A significant signal enhancement was observed in the vasculature and head, although with poor spatial resolution. 
(A)

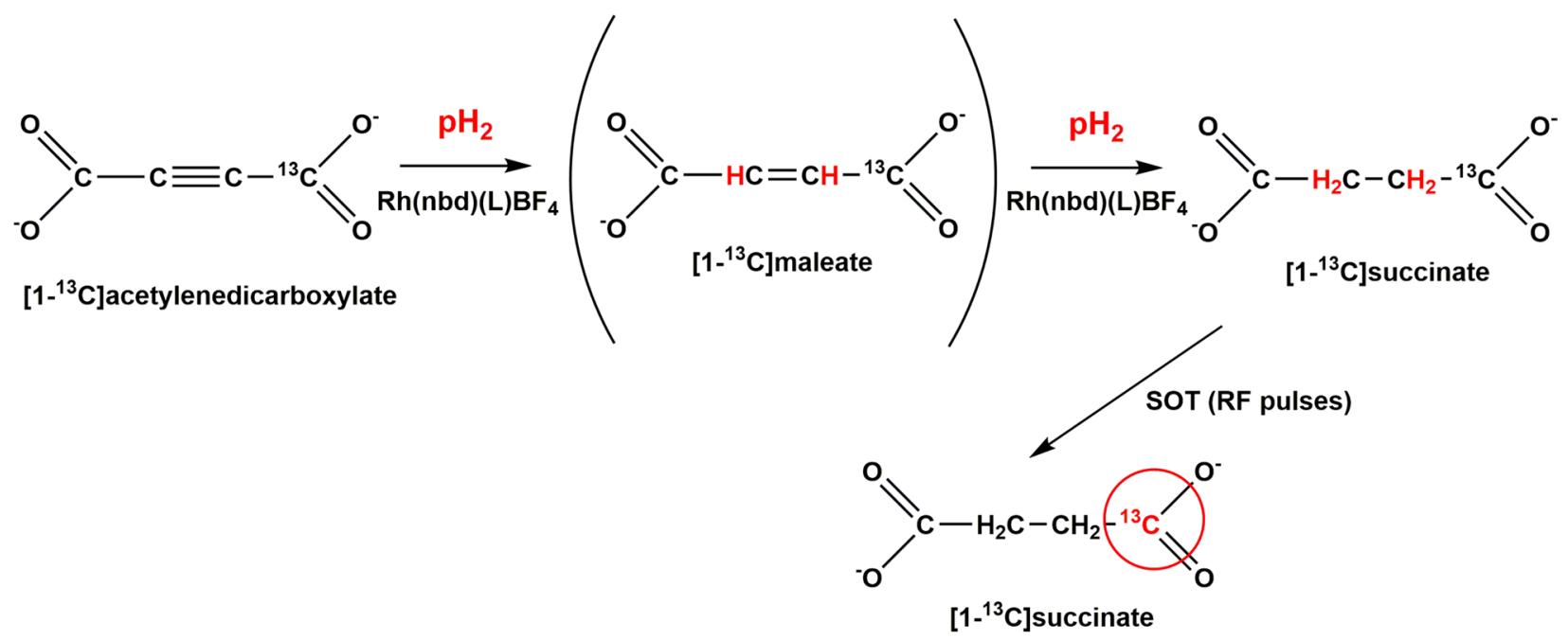

(B)

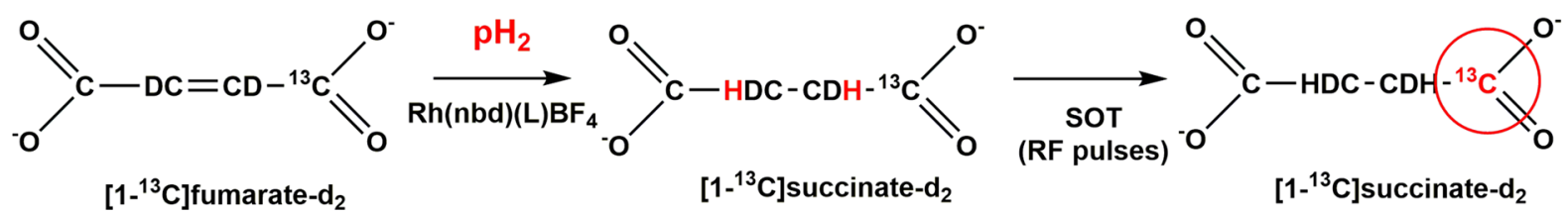

Fig. 8 Scheme reporting the key steps of the hyperpolarization procedure: a HP-Succinate: hydrogenation of $\left[1-{ }^{13} \mathrm{C}\right]$ acetylenedicarboxylate to $\left[1-{ }^{13} \mathrm{C}\right]$-maleate and then $\left[1-{ }^{13} \mathrm{C}\right]$ Succinate; b HP-Succinate: hydrogenation of $\left[1-{ }^{13} \mathrm{C}\right]$ fumarate- $\mathrm{d}_{2}$ to succinate. The reaction are carried out in aqueous solution and are catalysed by the water-soluble

When $\left[1-{ }^{13} \mathrm{C}\right]$ acetylenedicarboxylate is used as the substrate, toxic $\left[1-{ }^{13} \mathrm{C}\right]$ maleate is obtained as the first hydrogenation product (see Fig. 7), while succinate needs the addition of a second hydrogen molecule. This issue has been addressed using $\left[1-{ }^{13} \mathrm{C}\right]$ fumaric acid- $\mathrm{d}_{2}$ as substrate [79] (Fig. 7). The transfer of parahydrogen spin order to ${ }^{13} \mathrm{C}$ magnetization was also optimized, considering the dependence of scalar couplings among protons and ${ }^{13} \mathrm{C}$ on $\mathrm{pH}$, and $15-20 \%{ }^{13} \mathrm{C}$ polarization was obtained at the output of the reactor. It must be noticed that, since the transfer of spin order to heteronuclear polarization takes place through $\mathrm{J}$-couplings that depend on $\mathrm{pH},{ }^{13} \mathrm{C}$ polarization level can be notably changed by $\mathrm{pH}$. In particular, for $\mathrm{pH}$ values close to the $\mathrm{pKa}$ of succinic acid, the polarization transfer is hampered by exchange between succinic acid and succinate that disrupts in the ${ }^{1} \mathrm{H}-{ }^{13} \mathrm{C}$ coupling network. Therefore, the $\mathrm{pH}$ of the aqueous solution in which the hydrogenation was carried out was set to acidic. Another route to overcome this problem was proposed, where the parahydrogenation of the maleic anhydride led to succinic anhydride [84]. The process was carried out in an organic solvent and the succinic anhydride was then transformed into succinic acid by rapid hydrolysis after the hydrogenation step.
Rhodium(I) complex $[\mathrm{Rh}(\mathrm{nbd})(\mathrm{L})]\left[\mathrm{BF}_{4}\right]$, where $n b d$ norbornadiene and $L$ is the water soluble ligand 1,4-bis[(phenyl-3-propansulfonate) phosphine]butane. Spin order transfer from parahydrogen to ${ }^{13} \mathrm{C}$ is obtained by means of the application of RF pulses

Succinate was also used as a test substrate for automatized PHIP polarizers. [44, 81, 85]. The high ${ }^{13} \mathrm{C}$ polarization $(25-28 \%)$ and a concentration of the substrate $(\sim 30 \mathrm{mM})$ achieved using these devices made it suitable for in vivo applications.

The resulting HP $\left[1-{ }^{13} \mathrm{C}\right]$ succinate- $\mathrm{d}_{2}$ was used to demonstrate the feasibility of low-field molecular imaging (47.5 $\mathrm{mT}$ ) in vitro [81] and in vivo[85]. A clear advantage given by low field MRI is the ${ }^{13} \mathrm{C} \mathrm{T}_{1}$ of $\left[1-{ }^{13} \mathrm{C}\right]$ succinate- $\mathrm{d}_{2}$ in aqueous solution, $75 \pm 3 \mathrm{~s}$ at $47.5 \mathrm{mT}$ instead of $26.6 \pm 1.0 \mathrm{~s}$ at $4.7 \mathrm{~T}[79]$.

The metabolic transformation of PHIP polarized succinate was not observed, as also confirmed using the same metabolite polarized by means of d-DNP. This shows again, that the hyperpolarization method does not interfere with the metabolic processes.

The applicability of this hyperpolarized substrate as angiographic tracer can still be considered a viable possibility, in fact the first in vivo application of $\mathrm{a}^{13} \mathrm{C}$ hyperpolarized substance, made use of a PHIP polarized probe (hydroxyethyl propionate, HEP) as an angiographic reporter [6].

The use of metabolically inert hyperpolarized substrates as tracers of vascularization and perfusion in tissues was suggested, using d-DNP polarized molecules [86-88] and also water $[86,89]$. These agents may be considered useful 
alternatives to the currently used Gd-based MRI contrast agents that are largely used in the clinical settings to report about organ perfusion and abnormalities in the excretion pathways. Nowadays there is a growing concern about their use, since tiny amounts of gadolinium have been found in the brain and other tissues of patients undergone to multiple administrations of these agents [90]. Although no evidence for a clinical consequence associated with the presence of retained Gd has yet been reported, nevertheless there is an active search for possible metal-free alternatives. As the use of MRI Contrast Agents is a need for the radiologist in a number of diagnostic assessments, the availability of low cost, easily accessible PHIP systems might likely be considered also for this purpose.

\section{$\left[1-{ }^{13} \mathrm{C}\right]$ phospho-lactate}

The unsaturated precursor of phospo-lactate (PLac) is the nontoxic $\left[1-{ }^{13} \mathrm{C}\right]$ phosphoenolpyruvate (PEP). Here, the phosphate group stabilizes the double bond adjacent to the oxygen atom and it can be easily enzymatically cleaved without producing toxic byproducts. The hydrogenation catalyst used for the parahydrogenation reaction (Fig. 9) is the same used for parahydrogenation of $\left[1-{ }^{13} \mathrm{C}\right]$ fumarate to $\left[1-{ }^{13} \mathrm{C}\right]$ succinate, i.e., a water soluble rhodium complex, that remains in the aqueous solution of the hyperpolarized product.

A relevant increase of ${ }^{13} \mathrm{C}$ hyperpolarization on PLac, with respect to the early reported one for the protonated substrate $\left(1 \%{ }^{13} \mathrm{C}\right.$ polarization [91]), was obtained using the deuterated derivative $\left[1-{ }^{13} \mathrm{C}\right] \mathrm{PEP}-\mathrm{d}_{2}\left(15.6 \pm 3 \%{ }^{13} \mathrm{C}\right.$ polarization)[40]. The synthetic route for the deuteration of PLac has been improved recently [92]. Deuteration of this substrate leads to a simplified spin system which is an advantage for the polarization transfer procedure, because hyperpolarization is distributed among three spins instead of five. Being still coupled with the parahydrogen protons on the product molecule, but to a lesser extent than protons, deuterons allow to increase the hyperpolarization level. Selective deuteration of the substrates and, more interestingly, of the catalysts has been employed successfully in non-hydrogenative PHIP (SABRE), in which $50 \%$ polarization has been obtained on a derivative of nicotinamide (methyl-4,6- $d_{2}$-nicotinate) [21]. Another advantage of selective deuteration is given by the longer $\mathrm{T}_{1}$ with respect to the protonated analog, in fact the $T_{1}$ of $\left[1-{ }^{13} \mathrm{C}\right] \mathrm{PEP}-\mathrm{d}_{2}$ is $51 \pm 2 \mathrm{~s}$ at $5.75 \mathrm{mT}$, while the $\mathrm{T}_{1}$ of the protonated molecule is $36 \pm 2 \mathrm{~s}$ at the same field. ${ }^{13} \mathrm{C}$ polarization was increased also thanks to the optimization of the $\mathrm{pH}$ of the water solution in which the hyperpolarization procedure is carried out, in an analogous manner as for succinate hyperpolarization [79].

A good improvement in the concentration of the parahydrogenated product was also achieved, with respect to the initially reported one, yielding $\sim 30 \mathrm{mM}$ solution of HP $\left[1-{ }^{13} \mathrm{C}\right]$ PLac-d $\mathrm{d}_{2}$.

Bio-distribution studies of non-hyperpolarized PLac demonstrated that it undergoes fast dephosphorylation in vivo to yield $\left[1-{ }^{13} \mathrm{C}\right]$ lactate within $1 \mathrm{~min}$.[93]. An in vivo study carried out on mice using hyperpolarized $\left[1-{ }^{13} \mathrm{C}\right]$-phospholactate $25 \mathrm{mM}\left(\sim 15 \%{ }^{13} \mathrm{C}\right.$ polarization)[39] showed that the HP PLac can be detected, by means of ${ }^{13} \mathrm{C}$ slice-selective gradient echo (GRE) imaging at $4.7 \mathrm{~T}$, in the vasculature, in the heart and in the bladder of the animal. Unfortunately, the spectroscopic differentiation between PLac and lactate was not possible, in vivo, due to small chemical shift difference between the two molecules.

\section{Open issues and possible solutions}

Overall, the in vitro and in vivo studies so far reported for HP molecules generated by h-PHIP clearly demonstrate that they can represent reliable candidates for applications in the biomedical field and, in principle, potential competitors with the hyperpolarized molecules generated by d-DNP. Let's consider the current weaknesses and possible solutions to<smiles>[2H]C([2H])=C(OP(=O)(O)O)[14C](=O)O</smiles>

$1-{ }^{13} \mathrm{C}$-phosphoenolpyruvate-d2

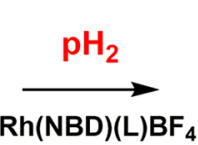

$1-{ }^{13} \mathrm{C}$-phospholactate-d2

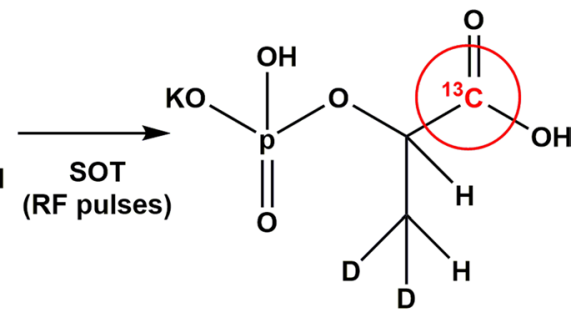

$1-{ }^{13}$ C-phospholactate-d2

Fig. 9 Hyperpolarization of $\left[1-{ }^{13} \mathrm{C}\right]$ phospholactate obtained from parahydrogenation of $\left[1-{ }^{13} \mathrm{C}\right]$ phosphoenoylpyruvate. The hydrogenation conditions are the same as for succinate (Fig. 7). Spin order transfer from parahydrogen to ${ }^{13} \mathrm{C}$ is obtained by means of the application of RF pulses 
make the h-PHIP generated molecules more suitable for the intended applications.

In vivo applications of HP probes need relatively high ${ }^{13} \mathrm{C}$ polarization levels and, albeit a few studies have been carried out using 3-4\% polarization (see, e.g., [94]), the hyperpolarization level usually reached on d-DNP products is $20-30 \%$ [57, 95]. Such values have been reached also for some of the previously reported PHIP substrates [37, 40, 79], but in other molecules, in particular those derived from PHIP-SAH procedure, the attained polarization level is still considerably lower, albeit it is already sufficient to carry out biological investigations. In the second part of this review one of our focus will deal with the determinants of the heteronuclear polarization obtained in PHIP experiments and on the methods that have been developed to tackle this issue.

Next, as the bio-compatibility of the administered solutions is fundamental requisite for in vivo applications; therefore, much attention has to be devoted to reduce as much as possible the presence of the hydrogenation catalyst and organic solvents to avoid toxicity problems. The strategies that have been investigated, to remove the toxic impurities from the aqueous solutions of the hyperpolarized substrates will be reported.

The concentration of the hyperpolarized probes, used for in vivo studies, is rather high, for example, the pyruvate concentration for in-vivo investigations in mice is $80 \mathrm{mM}$ [96] and $230 \mathrm{mM}$ in humans [57]. Since the parahydrogenated product must be obtained in few seconds, to avoid polarization losses during the hydrogenation reaction, the efficiency of the hydrogenation catalyst and of the hydrogenation system must be optimal.

These three points, heteronuclear polarization, biocompatibility of the solution and efficiency of the hydrogenation reaction, will be discussed in the second part of this review.

\section{From parahydrogen spin order to heteronuclear magnetization}

The introduction of parahydrogen induced polarization (PHIP) allowed for dramatically enhanced proton signals, and introduced the challenge of transferring polarization from proton singlet order to heteronuclei characterized by longer $T_{1}$. As far as biological applications are concerned, heteronuclear hyperpolarization allows also to benefit from zero background signal.

To get more insight on how heteronuclear hyperpolarization can be observed, and, possibly, increased on parahydrogenated molecules, it is useful to recall some basic quantum-mechanical descriptions of the PHIP phenomenon. A more thorough treatment can be found in other reviews. [14, 97, 98]

The simplest way to get an understanding of how heteronuclei become hyperpolarized, in parahydrogenated molecules, is to consider the population model of the NMR phenomenon. In terms of the spin functions $\alpha$ and $\beta$, the nuclear wavefunctions of the hydrogen molecule are $S_{0}=1 / \sqrt{2}|\alpha \beta-\beta \alpha\rangle, T_{-1}=|\alpha \alpha\rangle, T_{0}=1 / \sqrt{2}|\alpha \beta+\beta \alpha\rangle$, $T_{+1}=|\beta \beta\rangle$, the first is antisymmetric in exchange of the nuclei (this is the para state), while the other three are symmetric (the ortho states). Since transitions between states having different symmetry are not allowed, the first state is isolated form the other three and is a singlet state, while the others form a triplet state. At thermal equilibrium, the four states are almost equally populated as only tiny differences stem from the Boltzmann factor that is in the order of $10^{-5}$. In PHIP experiments one uses hydrogen that is enriched in the parahydrogen isomer, thus the para state is more populated. Different systems have been described that allow to obtain para-enriched hydrogen at different percentage, depending on the temperature reached inside the conversion chamber [99-101].

When hydrogenation, using para-enriched hydrogen, is carried out, the hydrogen molecule undergoes a sudden change and a new spin system is formed. For sake of simplicity we'll deal with a three spins system (AA'X) in which the third nucleus $(\mathrm{X})$ is a heteroatom and the energy levels are given by the Hamiltonian:

$\mathcal{H}=\mathcal{H}_{Z}+\mathcal{H}_{J}$

$\mathcal{H}_{Z}=-v_{H}\left(I_{z}^{A}+I_{z}^{A^{\prime}}\right)-v_{X} I_{z}^{X}$,

$\mathcal{H}_{J}=J_{A A^{\prime}}\left[I_{z}^{A} I_{z}^{A^{\prime}}+\frac{\left(I_{+}^{A} I_{-}^{A^{\prime}}+I_{-}^{A} I_{+}^{A^{\prime}}\right)}{2}\right]+J_{A X} I_{z}^{A} I_{z}^{X}+J_{A^{\prime} X} I_{z}^{A^{\prime}} I_{z}^{X}$,

where $\mathcal{H}_{Z}$ and $\mathcal{H}_{J}$ are the Zeeman and the J-coupling Hamiltonian, respectively. The nuclear spin wavefunctions can be calculated using the singlet-triplet states for the two protons and the Zeeman states for the heteronucleus as a suitable basis

$S_{0} \alpha, S_{0} \beta, T_{-1} \alpha, T_{-1} \beta, T_{0} \alpha, T_{0} \beta, T_{+1} \alpha, T_{+1} \beta$.

The eigenstates of the new spin system, using this Singlet-Triplet-Zeeman basis, are [101]

$$
\begin{gathered}
T_{-1} \alpha=|\alpha \alpha \alpha\rangle, T_{-1} \beta=|\alpha \alpha \beta\rangle, \\
S^{\prime} \alpha=\left|c_{11} S_{0} \alpha+c_{12} T_{0} \alpha\right\rangle, T_{0}^{\prime} \alpha=\left|c_{21} S_{0} \alpha+c_{22} T_{0} \alpha\right\rangle, \\
S^{\prime} \beta=\left|d_{11} S_{0} \beta+d_{12} T_{0} \beta\right\rangle, \quad T_{0}^{\prime} \beta=\left|d_{21} S_{0} \beta+d_{22} T_{0} \beta\right\rangle, \\
T_{+1} \alpha=|\beta \beta \alpha\rangle, T_{+1} \beta=|\beta \beta \beta\rangle, \text { where the spin order of par- }
\end{gathered}
$$
ahydrogen is distributed among the states $S^{\prime} \alpha, T_{0}^{\prime} \alpha, S^{\prime} \beta$, and $T_{0}^{\prime} \beta$.The states $S^{\prime} \alpha$ and $S^{\prime} \beta$ are more populated, according to the coefficients $c_{11}$ and $d_{11}$ (see [101] for the calculation of these values). As far as hyperpolarization of the heteronucleus is concerned, it can be observed that the transitions 
between the states $S^{\prime} \alpha \rightarrow T_{0}^{\prime} \beta$ and $S^{\prime} \beta \rightarrow T_{0}^{\prime} \alpha$ are hyperintense (hyperpolarized), because the population difference between these states is not dictated by the Boltzmann equilibrium, but is related to the para- $\mathrm{H}_{2}$ enrichment (see Fig. 9). According to this description, it clearly follows that heteronuclear hyperpolarization can be spontaneously obtained following the parahydrogenation of a substrate, provided that the heteroatom is asymmetrically coupled with the two protons, while the scalar interaction between the two protons is not truncated, i.e., the two protons are strongly coupled. It must be also evidenced that, if the parahydrogenation reaction is carried out at low magnetic field (i.e., in a Altadena experiment) [102] any proton network is strongly coupled and heteronuclear polarization can be observed with any spin system [103].

Heteronuclear hyperpolarization that is spontaneously generated in a parahydrogenation reaction corresponds to longitudinal two spin order and not to net magnetization. Using a product operator description, it can be said that hyperpolarized spin order is obtained, instead of net (longitudinal) magnetization. A short description in terms of product operators will be given too, to discuss the polarization transfer methods that were developed to increase the heteronuclear magnetization.

In terms of product operators, parahydrogen can be written as follows:

$$
\begin{aligned}
\sigma_{\mathrm{para}} & =\frac{1}{4} E-\left(I_{z}^{A} I_{z}^{A}+I_{x}^{A} I_{x}^{A}+I_{z}^{A} I_{x}^{A}+I_{y}^{A} I_{y}^{A}\right) \\
& =\frac{1}{4} E-\left[I_{z}^{A} I_{z}^{A}+\left(Z Q_{x}\right)^{A A}\right]
\end{aligned}
$$

where $E$ is the unity matrix, $I_{z}^{A} I_{z}^{A}$ is the proton-proton longitudinal spin order term and $\left(Z Q_{x}\right)^{A A}$ is the zero quantum coherence term $\left(\left(Z Q_{x}\right)^{A A}=\left(I_{x}^{A} I_{x}^{A}+I_{y}^{A} I_{y}^{A}\right)\right)$. Following to the addition of parahydrogen to an unsaturated substrate and the formation of an AA'X spin system, the Hamiltonian changes suddenly. The time evolution of the density operator is given by the commutator of the Liouville-Von Neumann equation:

$\frac{d \sigma_{\mathrm{para}}}{d t}=-i\left[\sigma_{\mathrm{para}}, \mathcal{H}\right]$

where $\mathcal{H}$ is the Hamiltonian of the $\mathrm{AA}^{\prime} \mathrm{X}$ system (1). The two spins order term $I_{z}^{A} I_{z}^{A}$ commutates with the Hamiltonian, i.e., it remains invariant under the action of the Hamiltonian, and the evolution of the initial parahydrogen polarization can be reduced to the evolution of the zero-quantum coherence term $\left(Z Q_{x}\right)^{A A}$. Starting from this term, we obtain [104]:

$$
\left\{2\left(I_{y}^{A} I_{x}^{A^{\prime}}-I_{x}^{A} I_{y}^{A^{\prime}}\right) I_{z}^{X}\right\}=\left\{2\left(Z Q_{y}\right)^{A A} I_{z}^{X}\right\},
$$

and proton-carbon spin order $\left\{\left(I_{z}^{A}-I_{z}^{A^{\prime}}\right) I_{z}^{X}\right\}$.
The (time dependent) density matrix becomes

$$
\begin{aligned}
\sigma(t)= & \frac{1}{4} E-I_{z}^{A} I_{z}^{A^{\prime}}-a(t)\left(Z Q_{x}\right)^{A A^{\prime}} \\
& -b(t) 2\left(Z Q_{y}\right)^{A A^{\prime}} I_{z}^{X}-c(t)\left(I_{z}^{A}-I_{z}^{A^{\prime}}\right) I_{z}^{X} .
\end{aligned}
$$

having time-dependent coefficients $a(t), b(t)$ and $c(t)$.

Since various molecules are hydrogenated at different times, the density matrix starts to evolve at different timepoints and, at the end of the hydrogenation, an average density matrix is obtained. The averaged coefficients, calculated by Natterer et al. [104], are.

$\bar{a}(t)=\left(\frac{J_{A A^{\prime}}}{J^{\prime}}\right), \quad \bar{b}(t)=0 \quad$ and $\quad \bar{c}(t)=\frac{J_{A A^{\prime}} J_{\Delta}}{\left(J^{\prime}\right)^{2}} \bar{c}(t)=\frac{J_{A A^{\prime}} J_{\Delta}}{\left(J^{\prime}\right)^{2}}$,

in which $J^{\prime}=\sqrt{J_{A A^{\prime}}^{2}+\left(J_{\Delta}\right)^{2}}$ and $J_{\Delta}=\frac{J_{A X}-J_{A^{\prime} X}}{2}$.

Therefore, it results clearly that the term $\left(Z Q_{y}\right)^{A A^{\prime}} I_{z}^{X}$ is averaged to zero and heteronuclear hyperpolarized signals are given by the spin order term $\left(I_{z}^{A}-I_{z}^{A^{\prime}}\right) I_{z}^{X}$, that corresponds to antiphase ${ }^{13} \mathrm{C}$ signals, as shown using the spin states populations.

Several different methods have been developed to optimize the transfer of parahydrogen spin order to longitudinal heteronuclear magnetization, some based on magnetic field cycling and other that make use of RF pulse sequences.

\section{Magnetic field cycle}

Longitudinal polarization on a heteronucleus has been obtained, for the first time, following a diabatic-adiabatic magnetic field cycling (MFC) process. [5, 75] In this process, the hydrogenation is performed in a static magnetic field high enough to warrant the truncation of all scalar interaction between different nuclear species. Then the field is suddenly (diabatically) decreased so that the populations of the spin states are redistributed, with respect to high field. When the field is slowly (adiabatically) raised to the initial value, the populations of the instantaneous eigenstates remain constant. The populations of the original eigenstates are rearranged and the systems displays a heteronuclear NMR spectrum, where the transitions are predominantly in-phase (Fig. 10).

For fields greater than the geomagnetic field $(\sim 50 \mu \mathrm{T})$ the high field regime is fulfilled, i.e., the scalar interaction between protons and carbon is truncated, and the effective Hamiltonian is, for the AA'X system, the same as in Eq. 1.

Immediately after the hydrogenation step, the magnetic field is suddenly dropped to few tens of nano Tesla (30-50 nT), where the J-coupling Hamiltonian differs from the high-field one (Eq. 3) by the addition of flip-flop terms $\left(\frac{1}{2}\left(I_{+}^{A} I_{-}^{X}+I_{-}^{A} I_{+}^{X}\right)\right.$ and $\left.\frac{1}{2}\left(I_{+}^{A^{\prime}} I_{-}^{X}+I_{-}^{A^{\prime}} I_{+}^{X}\right)\right)$ between heteronuclear spin pairs: 

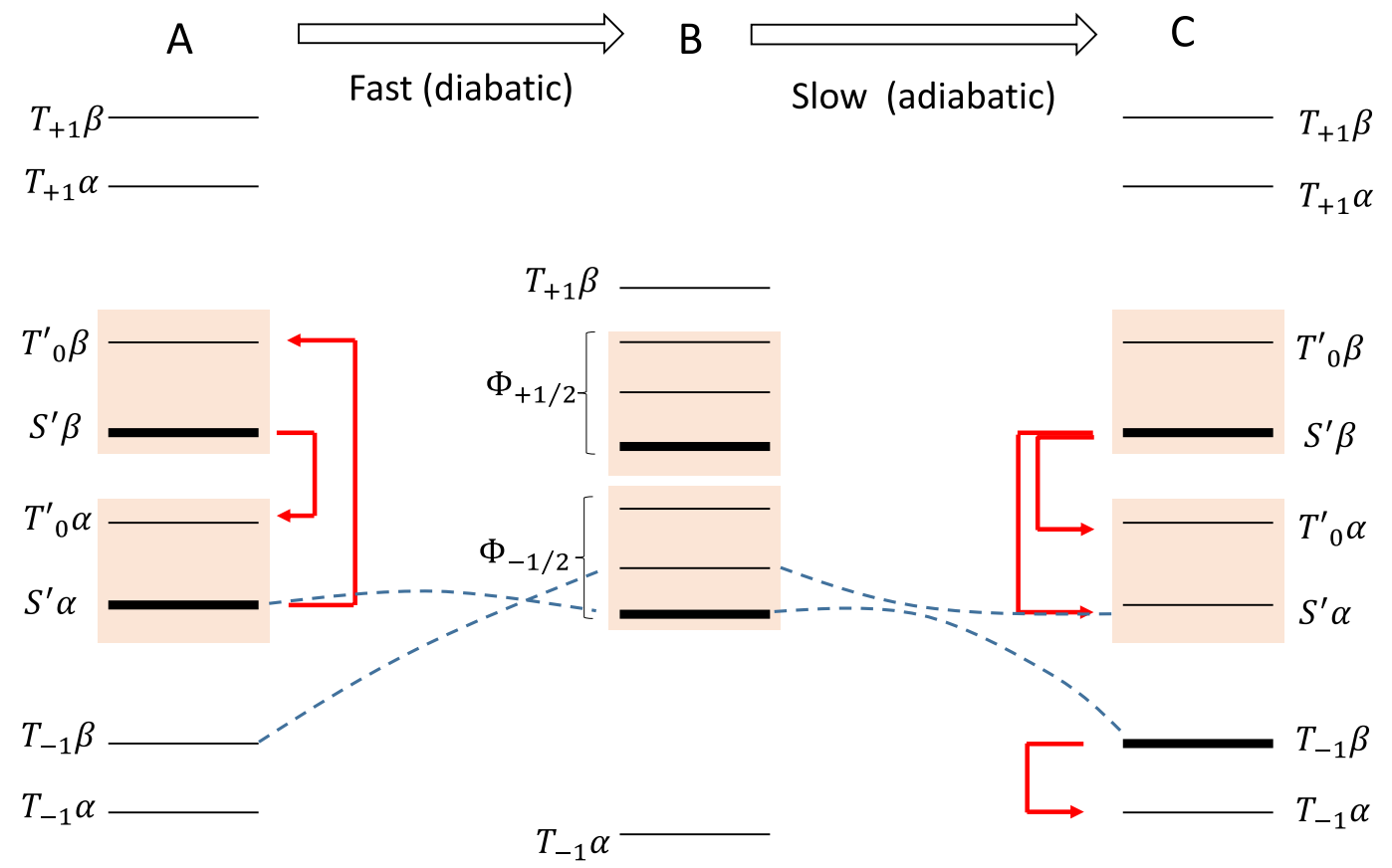

$\mathrm{B}_{0}=50 \mu \mathrm{T}$

$\mathrm{B}_{0}<50 \mathrm{nT}$

$\mathrm{B}_{0}=50 \mu \mathrm{T}$
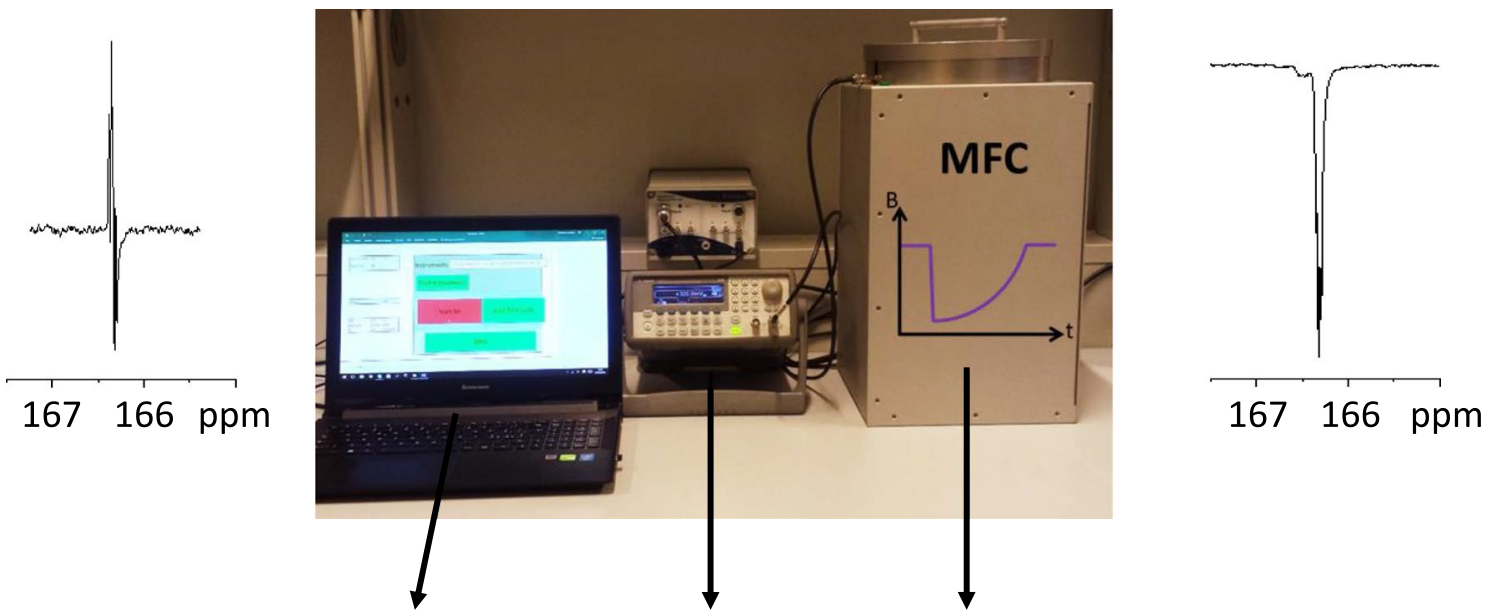

\section{Current circuit controller \\ Current generator \\ $3 \mu$-metal shields \\ + solenoid}

Fig. 10 Upper panel: diagram representing the population of the nuclear spin states in a AA'X system: a population of the nuclear spin state after the parahydrogenation reaction at geomagnetic field $(\sim 50 \mu \mathrm{T})$; $\mathbf{b}$ after a diabatic (fast) decrease of the magnetic field to few nT, the population of the spin stats are re-arranged; $\mathbf{c}$ when the magnetic field is adiabatically increased again. Dashed lines evidence the crossing (on the left) and avoided crossing (LAC, on the right) of the spin states in the two asymmetric passages. The red arrows represent the hyper-intense (hyperpolarized) transitions of the het- eronucleus. Lower panel: ${ }^{13} \mathrm{C}-\mathrm{NMR}$ signal of a symmetric product: a before the application of MFC, antiphase hyperpolarized signals are observed for the heteronucleus, $\mathbf{c}$ after the application of magnetic field cycle, net magnetization is obtained. In the central panel is reported a photo of the system used for the application of MFC: it consists in a mu-metal shield, an arbitrary wavefunction generator for the application of controlled current to the coil and a computer to control the applied current. More details can be found in [111] 
$\mathcal{H}_{J}=J_{A A^{\prime}}\left[I_{z}^{A} I_{z}^{A^{\prime}}+\frac{\left(I_{+}^{A} I_{-}^{A^{\prime}}+I_{-}^{A} I_{+}^{A^{\prime}}\right)}{2}\right]+J_{A X}\left[I_{z}^{A} I_{z}^{X}+\frac{\left(I_{+}^{A} I_{-}^{X}+I_{-}^{A} I_{+}^{X}\right)}{2}\right]+J_{A^{\prime} X}\left[I_{z}^{A^{\prime}} I_{z}^{X}+\frac{\left(I_{+}^{A^{\prime}} I_{-}^{X}+I_{-}^{A^{\prime}} I_{+}^{X}\right)}{2}\right]$

The eigenstates can be calculated, using the basis (4):

$\Phi_{-3 / 2}=T_{-1} \alpha \quad \Phi_{+3 / 2}=T_{+1} \beta$,

sequence employs two channels $\left({ }^{1} \mathrm{H}\right.$ and heteronuclear) at the same time and provides a route to controlled and selective isotropic mixing between different nuclei.

$\Phi_{-1 / 2}=c_{11} T_{-1} \beta+c_{12} S_{0} \alpha+c_{13} T_{0} \alpha \quad \Phi_{+1 / 2}=d_{11} T_{+1} \alpha+d_{12} S_{0} \overline{\beta+d_{13} T_{0} \beta}$,

$\Phi_{-1 / 2}^{\prime}=c_{21} T_{-1} \beta+c_{22} S_{0} \alpha+c_{23} T_{0} \alpha \quad \Phi_{+1 / 2}^{\prime}=d_{21} T_{+1} \alpha+d_{22} S_{0} \beta+d_{23} T_{0} \beta$,

$\Phi \prime \prime-1 / 2=c_{31} T_{-1} \beta+c_{32} S_{0} \alpha+c_{33} T_{0} \alpha \quad \Phi \prime \prime{ }_{+1 / 2}=d_{31} T_{+1} \alpha+d_{32} S_{0} \beta+d_{33} T_{0} \beta$,

where the three states $\left(T_{-1} \beta-S_{0} \alpha-T_{0} \alpha\right)$ and $\left(T_{+1} \alpha-S_{0} \beta-T_{0} \beta\right)$ are mixed. The population of the states at zero field depends, again, on the coefficients $c$ and $d$ of the $S_{0} \alpha$ or $S_{0} \beta$ basis states.

During the adiabatic transfer from low field to intermediate field, the Eigenstates at zero field evolve slowly into the Eigenstates characteristic of an intermediate field and the populations of the instantaneous Hamiltonian are left unchanged. The Eigenstates and eigenvalues for an arbitrary field can be calculated using numerical methods and the continuous transformation from low to intermediate field can be monitored, to find the correlations between zero and intermediate field. The result is a net polarization of the ${ }^{13} \mathrm{C}$ spins instead of the initial ${ }^{1} \mathrm{H}^{13} \mathrm{C}$ spin order. The theoretical efficiency of spin order transfer, i.e., the maximum polarization obtainable, depends on the J-couplings and on the number of spins involved. It is higher when the system is formed by only three spins (the two protons from parahydrogen and the heteroatom) and becomes lower when the number of spins increases.

An alternative field-cycling method has been recently proposed, together with an accurate theoretical description of the dynamics of the spin system, in which the applied magnetic field is adiabatically swept from a negative to a positive value, passing through zero. [77]

Another strategy to achieve spin mixing is by means of strong resonant field, that is, under spin-locking conditions. The application of resonant RF excitation at the NMR frequencies of protons and heteronuclei brings the system to a level anti-crossing (LAC, also termed avoided level crossing), where efficient spin mixing occurs [105]. This

\section{RF pulses based methods for spin order transfer}

Several pulse sequences have been developed to transform the singlet order of parahydrogen into heteronuclear magnetization.

The first NMR pulse sequences to transfer the parahydrogen induced polarization to heteronuclei were reported by Haake et al. [106] and are based on the INEPT sequence. They were named PH-INEPT and PH-INEPT+, and were applied to molecules in which heteronuclear polarization was not spontaneously created. This occurs when the two parahydrogen protons are added to chemically different sites, in a strong magnetic field, and the weak coupling condition among protons applies. If a three spins system, formed by the two parahydrogen protons $\left(H_{A}\right.$ and $\left.H_{X}\right)$ and one heteroatom $(X)$, is considered, the Zeeman $\left(\mathcal{H}_{Z}\right)$ and J-coupling Hamiltonian $\left(\mathcal{H}_{J}\right)($ Eq. 1) become, in this case

$\mathcal{H}_{Z}=-v_{H_{A}}\left(I_{z}^{H_{A}}\right)-v_{H_{X}}\left(I_{z}^{H_{X}}\right)-v_{X} I_{z}^{X}$,

$\mathcal{H}_{J}=J_{H_{A} H_{X}}\left(I_{z}^{H_{A}} I_{z}^{H_{X}}\right)+J_{H_{A} X}\left(I_{z}^{H_{A}} I_{z}^{X}\right)+J_{H_{X} X}\left(I_{z}^{H_{X}} I_{z}^{X}\right)$.

These are the so-called Pasadena experiments [12]. The spin order term $I_{z}^{H_{A}} I_{z}^{H_{X}}$ commutes with the Hamiltonian; therefore, it remains invariant, while from the evolution of the zero-quantum coherence $\left(Z Q_{x}=\left(I_{x} I_{x}+I_{y} I_{y}\right)\right)$, the term $\left.2\left(I_{y}^{H_{A}} I_{x}^{H_{X}}-I_{x}^{H_{A}} I_{y}^{H_{X}}\right) I_{z}^{X}\right)$ is formed. Both zero quantum coherence terms are time dependent and oscillate around zero, so they are zero-averaged and the parahydrogen derived density operator simplifies to $\sigma_{\text {Pasadena }}=\frac{1}{4} E-I_{z}^{H_{A}} I_{z}^{H_{X}}$. The INEPT based RF pulse sequences, such as the PH-INEPT, 
PHINEPT +, 1-PHINEPT + [80] and ESOTHERIC [35] act on this part of the parahydrogen density operator.

Other pulse sequences were developed to improve the efficiency of spin order transfer from parahydrogen to heteronuclei. The sequence developed by Golman and coworkers [76, 107] exploits the term $\left(Z Q_{y}\right)^{A A^{\prime}} I_{z}^{X}$ (that results according to Eq. 6 for an AA'X spin system). When using this sequence, the hydrogenation step takes place under a strong RF irradiation at the proton Larmor frequency. This disconnects the singlet state from the triplet state, thereby maintaining it until the hydrogenation ends. At this point it is stopped and all the spins starts to evolve coherently. The first part of the sequence tends to maximize the term $\left(Z Q_{y}\right)^{A A^{\prime}} I_{z}^{X}$, while the second part converts this term into ${ }^{13} \mathrm{C}$ net polarization.

The efficiency of the pulse sequence in transferring spin order to ${ }^{13} \mathrm{C}$ magnetization depends on the relative strengths of the three internuclear J-couplings. In particular, it is close to unity if the so-called Goldman angle $\theta=\arctan \frac{J_{H H}}{\frac{1}{2}\left(J_{H 1 C}-J_{H 2 C}\right)}$ [76] is near to $45^{\circ}$, i.e., for molecules in which parahydrogen protons are coupled with the target heteronucleus through relatively large scalar couplings. If this is not the case, the work by Kadlecek et al. proposed a more general solution [108].

Other sequences for spin order transfer have been initially developed to store hyperpolarized magnetization into singlet order. In fact, it may be noticed that hydrogenation reactions with para-enriched hydrogen yield a product that has strongly enhanced nuclear singlet order; therefore, these techniques can also be exploited to convert the parahydrogen derived singlet order into magnetization. The SLIC [109] and the S2hM (Singlet to heteronuclear Magnetization) sequence $[26,73,110]$ were adapted to perform singlet to heteronuclear magnetization transfer. These sequences operate in the near-equivalent regime, in which the two nuclei involved in the singlet state have a much stronger J-coupling between them than any other interaction that breaks the symmetry, such as chemical shift difference or asymmetric J-couplings with other nuclei. The application of these pulse sequences involves manipulations at low magnetic field, to minimize proton chemical shift differences. Problems may arise, since low-field electromagnets suffer from instability and drift and have a limited homogeneity. The robustness of these sequences to resonance offsets has also been investigated [110].

\section{Hydrogenation catalysis}

In PHIP procedures, the hydrogenation step is crucial, because it is instrumental to transform the singlet order of parahydrogen into hyperpolarization. This process takes place provided that the two protons of hydrogen are pairwise added to the same substrate molecule.

It is important to consider that the proton polarization, in the product molecules, is invariantly limited by the catalytic process. Thus the proton polarization observed in a hydrogenated substrate is substantially lower than the ideal case, in which the singlet order is completely transferred to the product molecule. This is usually observed when Pasadena or Altadena experiments are carried out (see, e.g., $[63,111]$ ) and can be termed the polarization transfer efficiency (PTE) [112]. PTE is the ratio between the polarization experimentally obtained on the product (regardless of the $\mathrm{T}_{1}$ relaxation of the hyperpolarized product) and the ideal case in which no polarization is lost during the catalytic cycle.

If the proton singlet order would be transferred directly to the product, without being affected by the reaction intermediates, PTE would be 1, but, in real cases, the hyperpolarization observed on the products depends on decoherence in the hydrogenation intermediates, where singlet and triplet states are mixed. This was already evident in the early studies about PHIP [104], and then nicely described by Berner et al.[44]. It was observed that hydrogenation intermediates strongly affect resulting pattern of hyperpolarized NMR signals. Therefore, the hydrogenation catalysts, the stability of reaction intermediates and, more generally, the conditions of the hydrogenation reaction (hydrogen pressure, temperature, solvents) are crucial in determining the polarization level on protons and, consequently, on heteronuclei [113].

The most widely applied hydrogenation catalyst for PHIP hyperpolarization is a rhodium complex containing a bi-dentated phosphine. The hydrogenation pathway carried out by this kind of complexes, the so-called unsaturated route, is such that, firstly, the unsaturated substrate is added to the metal center and then the hydrogen molecule is almost directly transferred to the coordinated substrate, with very short-living, and undetectable, reaction intermediates [114, 115]. Thanks to this pathway, mixing between the singlet and the triplet states should be minimized on intermediates, nevertheless the PTE is still far from unity. In a recent publication, the effect of different ligands on hydrogenation and hyperpolarization efficiency [116] has been explored and it has been shown that rhodium complexes with electrondonating bisphosphine ligands appear to be more effective than conventional rhodium catalysts.

A fundamental requirement for the application of PHIP polarized molecules to biological investigations is that the solution of the hyperpolarized probe molecule must be aqueous, therefore, organic solvents (such as methanol- $\mathrm{d}_{4}$ and acetone- $\mathrm{d}_{6}$ ), in which these hydrogenation catalysts are usually employed, cannot be used. This is a strong limitation, because hydrogenation catalysis is more efficient in organic solvents than in water, thanks also to higher $\mathrm{H}_{2}$ solubility. The hydrogenation and phase extraction method has been 
introduced for parahydrogen hyperpolarization of lipophilic substrates such as anhydrides or esters that can be transformed into hydrophilic molecules by means of hydration or hydrolysis reactions [32, 84]. In this case, the hydrogenation reaction is carried out in a hydrophobic organic solvent that, following to the addition of the aqueous solution, forms a separate phase in which the hydrogenation catalyst is retained. The advantages are given by the fact that hydrogenation is more efficient thanks to the use of the organic solvent and, at the same time, the catalyst is not present in the aqueous solution of the final product. However, it can be applied only to a limited number of substrates.

A water-soluble bis-phosphine ligand has also been widely applied to obtain the analogous rhodium complex suitable for hydrogenation in aqueous phase [79, 82, 91], nevertheless, in this case, a limitation to in vivo applications might be given by the concentration of the rhodium complex in the solution of the hyperpolarized product. Early investigations of rhodium based hydrogenation catalyst have shown relatively low toxicity [117], anyway more detailed studies have to be planned. The use of metal scavengers has been proposed, for removal of the Ir catalysts used in SABRE hyperpolarization [118] and the same principle, using an appropriate scavenger, could be applied for removal of the rhodium complexes.

Precipitation and filtration of the hyperpolarized products is an intriguing method for the purification of the hyperpolarized molecules. The preliminary studies carried out using thermally polarized fumarate [119] demonstrate that this molecule, thanks to its specific physic-chemical properties, can be easily precipitated from an aqueous solution at acidic $\mathrm{pH}$ and then readily dissolved at neutral $\mathrm{pH}$. To minimize relaxation, it is important to maintain the sample at high magnetic field during the passage between different states (liquid to solid and vice-versa).

Heterogeneous catalysts are attractive, because they can be separated from the solution of the product by filtration, but, unlike homogeneous hydrogenation which takes place on a well-defined metal center, heterogeneous hydrogenation proceeds over a surface of a metal cluster, where dissociative chemisorption of hydrogen molecules prevents pairwise addition of parahydrogen and leads to loss of singlet spin order. The use of immobilized complexes seemed the most straightforward way to combine the advantages of homogeneous and heterogeneous catalysis, and heterogeneous PHIP has been observed in the liquid phase using rhodium complexes immobilized over $\mathrm{SiO}_{2}$ [120]. Rather unexpectedly, supported metal catalysts leaded to PHIP effect that were observed in the gas phase $\left(\mathrm{Pt} / \mathrm{Al}_{2} \mathrm{O}_{3}\right.$ and $\mathrm{Pd} / \mathrm{Al}_{2} \mathrm{O}_{3}$ [121]) and in solution $\left(\mathrm{Rh} / \mathrm{TiO}_{2}\right.$ and $\mathrm{Rh} / \mathrm{AlO}(\mathrm{OH})$ [122-124]). The rhodium particles supported on beads of $\mathrm{TiO}_{2}(2-3 \mathrm{~mm})$ were also applied to the aqueous phase hydrogenation of vinyl acetate $[125,126]$. Unfortunately, the low pairwise selectivity of hydrogenation limited the hyperpolarization level. Surface diffusion can be limited by ligands that binds to the catalyst surface and stable, water soluble nanoparticles capped with amino-acid ligands (L-cysteine and $\mathrm{N}$-acetylcysteine) have been tested for parahydrogenation of different substrates [45, 127]. Nevertheless, the concentration of substrates used with these catalysts are usually quite small (less than $1 \mathrm{mM}$ ) and the filtration procedure to separate $2 \mathrm{~nm}$ nanoparticles appears quite challenging and cannot be mitigated by decantation of the HP fluid during a time frame that is compatible with the ${ }^{13} \mathrm{C} \mathrm{T}_{1}$.

PtSn intermetallic nanoparticles, encapsulated in mesoporous silica (PtSn@ $\mathrm{mSiO}_{2}$ [128]) were also reported to give intense polarized ${ }^{1} \mathrm{H}-\mathrm{NMR}$ signals in $\mathrm{D}_{2} \mathrm{O}$, thanks to the effect of incorporated $\mathrm{Sn}$ on the pairwise selectivity of hydrogenation.

In general, all these strategies need to be optimized and investigated to reach the final goal and to obtain a pure aqueous solution of the h-PHIP polarized substrate, suitable for in-human investigations.

\section{PHIP polarizers}

Since the first in vivo application of PHIP polarized substrates [5], which was also the first ${ }^{13} \mathrm{C}$ MRI in-vivo, several automated systems have been developed for the production of doses of hyperpolarized molecules that can be suitable for imaging purposes.

In the so-called laminar flow polarizers, hydrogenation occurs in a reaction chamber pressurized with parahydrogen (7-8 bar), in which the solution of reagents (substrate and catalyst) is injected. The hydrogenation chamber is placed in a low filed NMR unit made of low electromagnetic field (1.4 $\mathrm{mT}$ in the first reported set-up [83] and $\sim 5 \mathrm{mT}$ in other developed successively [39]) equipped with coils for the application of the RF pulse sequences that allow the transfer of spin order from parahydrogen protons to ${ }^{13} \mathrm{C}$ magnetization [84, $129,130]$. Thanks to the fact that the fast parahydrogenation reaction is carried out in a low-field MR unit, it can be synchronized with the pulse sequence. During the reaction time course, continuous wave decoupling can be applied to freeze the singlet state, a requirement that arises, since various molecules are hydrogenated at different times and the density matrix would, therefore, start to evolve at different time points, so spin order partly is lost. In a particular setup, placing the hydrogenation chamber in a $48 \mathrm{mT}$ Halbach magnet, allows the in-situ detection of parahydrogen hyperpolarization [131].

Unfortunately, none of these systems is commercial, but detailed descriptions are provided by the literature. An automated PHIP-polarizer equipped with relatively low cost open source software and hardware which allows replication has 
been reported. The reactor is settled at $B_{0}$ field of $\sim 5.75 \mathrm{mT}$; the hydrogenation can be performed in the range $40-75{ }^{\circ} \mathrm{C}$ and up to 21 atm (usually $\sim 6$ atm of $90 \%$ parahydrogen gas are used); during the reaction, ${ }^{1} \mathrm{H}$ decoupling is provided by the RF pulse sequence. In situ ${ }^{13} \mathrm{C}$ polarimetry of the produced hyperpolarized contrast agent can also be achieved.

An alternative way to overcome the necessity of a polarizer has been introduced by the synthesis amid the magnet bore, a dramatically enhanced nuclear alignment (SAMBADENA) [44, 113, 132]. The production of HP tracers can be achieved by hydrogenating the precursors in a reactor that is placed inside the bore of a commercial MRI system. In this case, the hardware of the system itself is used for the application of rf pulses for spin order transfer and for the detection of the MR signal, at the same site of polarization.

Another kind of set-up is often used, in PHIP experiments, in which the reaction is carried out by means of parahydrogen bubbling, at high pressure, in a NMR tube containing the solution of substrate and catalyst. In this case, the reaction can take place into the NMR spectrometer and the control of parahydrogen pressure and flow can be interfaced with the spectrometer, via magnetic valves [133], thus allowing to coordinate the reaction and the RF pulses. This kind of set-ups is easier to build than the spray-injection polarizers operating at high pressure and temperature. Unfortunately, the hydrogenation efficiency is considerably lower and the substrate conversion takes several seconds, while the ultra-fast reaction (3-5 s) that can be obtained in spray-injection polarizers prevents ${ }^{1} \mathrm{H}$ hyperpolarization losses due to relaxation during the time course of the reaction.

\section{Conclusions and outlook}

The access to hyperpolarized bio-molecules that act as in vivo reporters has paved the way to study metabolism with Magnetic Resonance Imaging and Spectroscopy. Whereas most of currently reported in in vivo studies have been carried out with molecules hyperpolarized by the d-DNP technology, there is sufficient evidence to anticipate that also PHIP generated systems will have a role in this field. Whereas, in d-DNP the source for the polarization transfer is provided by unpaired electrons, in the case of PHIP the source is represented by parahydrogen. As outlined in the above paragraphs, a limitation of PHIP deals with the need of the availability of an unsaturated precursor for the target molecule. Hydrogenative PHIP has found some solution to this fundamental issue, nevertheless some weaknesses can still be noticed, that are the presence of toxic impurities and, in some cases, the hyperpolarization level.

Concerning the toxic impurities in the solutions of the HP probes, it must be evidenced that, in some cases, these have been reduced to little more than traces $[40,66]$. Furthermore, the metabolic studies carried out, with some of the reported substrates, in-cells $[65,66]$ and in-vivo [67, 117] showed that the HP solutions are well tolerated and the results are consistent with biological investigations. This provides evidence that PHIP polarized substrates are promising probes for in vivo biological investigations. Nevertheless, work has still to be done to reduce those substances, especially on a clinical translation perspective.

As far as the increase of the hyperpolarization level is concerned, h-PHIP can already benefit from the research which has been dedicated to improve the spin order transfer from parahydrogen protons to heteronuclei, in different kind of products. Besides these quantum-mechanical aspects, much attention has still to be focused on the chemistry of the hyperpolarization procedure, in particular on the hydrogenation catalysis. Nevertheless, the advancements in this field must always keep an eye on the biocompatibility of the final solution, as well as on the high amount of the HP product that must be obtained, in few seconds.

In the end, the development of a dedicated polarizer, able to provide highly standardized HP products, endowed all the requirements (bio-compatibility of the solutions, concentration of the HP gent and hyperpolarization level) needed for in-vivo pre-clinical studies, in different research sites, will be necessary to foster the clinical translation of these promising HP probes.

Funding Open Access funding provided by Università degli Studi di Torino. This study was funded by the EU (Marie Skłodowska-Curie Grant Agreement No. 766402 and H2020 FETOPEN 2018-2020, No. 858149, AlternativesToGd.

\section{Compliance with ethical standards}

Conflict of interest FR and SA are inventors on a patent owned by Bracco Imaging SpA, related to this work.

Ethical approval This article does not contain any original study with animals performed by any of the authors.

Open Access This article is licensed under a Creative Commons Attribution 4.0 International License, which permits use, sharing, adaptation, distribution and reproduction in any medium or format, as long as you give appropriate credit to the original author(s) and the source, provide a link to the Creative Commons licence, and indicate if changes were made. The images or other third party material in this article are included in the article's Creative Commons licence, unless indicated otherwise in a credit line to the material. If material is not included in the article's Creative Commons licence and your intended use is not permitted by statutory regulation or exceeds the permitted use, you will need to obtain permission directly from the copyright holder. To view a copy of this licence, visit http://creativecommons .org/licenses/by/4.0/. 


\section{References}

1. Golman K, Olsson LE, Axelsson $\mathrm{O}$, Månsson S, Karlsson M, Petersson JS (2003) Molecular imaging using hyperpolarized ${ }^{13}$ C. Br J Radiol 76(Spec No):S118-S127

2. Ardenkjaer-Larsen JH, Fridlund B, Gram A, Hansson G, Hansson L, Lerche MH, Servin R, Thaning M, Golman K (2003) Increase in signal-to-noise ratio of $>10,000$ times in liquid-state NMR. Proc Natl Acad Sci U S A 100:10158-10163

3. Kurhanewicz J, Vigneron DB, Ardenkjaer-Larsen JH, Bankson JA, Brindle K, Cunningham CH, Gallagher FA, Keshari KR, Kjaer A, Laustsen C, Mankoff DA, Merritt ME, Nelson SJ, Pauly JM, Lee P, Ronen S, Tyler DJ, Rajan SS, Spielman DM, Wald L, Zhang X, Malloy CR, Rizi R (2019) Hyperpolarized ${ }^{13}$ C MRI: path to clinical translation in oncology. Neoplasia (United States) 21:1-16

4. Nikolaou P, Goodson BM, Chekmenev EY (2015) NMR hyperpolarization techniques for biomedicine. Chem A Eur J 21:3156-3166

5. Golman K, Axelsson O, Johannesson H, Månsson S, Olofsson C, Petersson JS (2001) Parahydrogen-induced polarization in imaging: subsecond C-13 angiography. Magn Reson Med 46:1-5

6. Olsson LE, Chai CM, Axelsson O, Karlsson M, Golman K, Petersson JS (2006) MR coronary angiography in pigs with intraarterial injections of a hyperpolarized ${ }^{13} \mathrm{C}$ substance. Magn Reson Med 55:731-737

7. Golman K, Ardenkjær-Larsen JH, Petersson JS, Månsson S, Leunbach I (2003) Molecular imaging with endogenous substances. Proc Natl Acad Sci U S A 100:10435-10439

8. Golman K, in 't Zandt R, Thaning M, (2006) Real-time metabolic imaging. Proc Natl Acad Sci U S A 103:11270-11275

9. Ardenkjær-Larsen JH, Bowen S, Petersen JR, Rybalko O, Vinding MS, Ullisch M, Nielsen NC (2019) Cryogen-free dissolution dynamic nuclear polarization polarizer operating at $3.35 \mathrm{~T}, 6.70$ T, and 10.1 T. Magn Reson Med 81:2184-2194

10. Ardenkjaer-Larsen JH, Leach AM, Clarke N, Urbahn J, Anderson D, Skloss TW (2011) Dynamic nuclear polarization polarizer for sterile use intent. NMR Biomed 24:927-932

11. Bowers C (1986) Transformation of symmetrization order to nuclear-spin magnetization by chemical reaction and nuclear magnetic resonance. Phys Rev Lett 57:2645-2648

12. Bowers CR, Weitekamp DP (1987) Parahydrogen and synthesis allow dramatically enhanced nuclear alignment. J Am Chem Soc 109:5541-5542

13. Duckett SB, Sleigh CJ (1999) Applications of the parahydrogen phenomenon: a chemical perspective. Prog Nucl Magn Reson Spectrosc 34:71-92

14. Green RA, Adams RW, Duckett SB, Mewis RE, Williamson DC, Green GGR (2012) The theory and practice of hyperpolarization in magnetic resonance using parahydrogen. Prog Nucl Magn Reson Spectrosc 67:1-48

15. Hovener AJ, Pravdivtsev AN, Kidd B, Bowers R, Glöggler S, Kovtunov KV, Katz-brull R, Buckenmaier K, Reineri F, Theis T, Roman V, Wagner S, Zacharias NMM, Chekmenev EY (2018) Parahydrogen-based hyperpolarization for biomedicine. Angew Chemie Int Ed. https://doi.org/10.1002/anie.201711842

16. Hövener J-B, Schwaderlapp N, Lickert T, Duckett SB, Mewis RE, Highton LR, Kenny SM, Green GGR, Leibfritz D, Korvink JG, Hennig J, von Elverfeldt D (2013) A hyperpolarized equilibrium for magnetic resonance. Nat Commun 4:2946

17. Joalland B, Ariyasingha NM, Lehmkuhl S, Theis T, Appelt S, Chekmenev EY (2020) Parahydrogen-induced radio amplification by stimulated emission of radiation. Angew Chemie Int Ed 59:8654-8660

18. Pravdivtsev AN, Sönnichsen FD, Hövener JB (2020) Continuous radio amplification by stimulated emission of radiation using parahydrogen induced polarization (PHIP-RASER) at 14 tesla. ChemPhysChem 21:667-672

19. Adams RW, Aguilar JA, Atkinson KD, Cowley MJ, Elliott PIP, Duckett SB, Green GGR, Khazal IG, Lopez-Serrano J, Williamson DC (2009) Reversible interactions with para-hydrogen enhance NMR sensitivity by polarization transfer. Science 323:1708-1711

20. Atkinson KD, Cowley MJ, Elliott PIP, Duckett SB, Green GGR, López-Serrano J, Whitwood AC (2009) Spontaneous transfer of Parahydrogen derived spin order to pyridine at low magnetic field. J Am Chem Soc 131:13362-13368

21. Rayner PJ, Burns MJ, Olaru AM, Norcott P, Fekete M, Green GGR, Highton LAR, Mewis RE, Duckett SB (2017) Delivering strong $1 \mathrm{H}$ nuclear hyperpolarization levels and long magnetic lifetimes through signal amplification by reversible exchange. Proc Natl Acad Sci U S A 114:E3188-E3194

22. Pravdivtsev AN, Hövener JB (2019) Simulating non-linear chemical and physical (CAP) dynamics of signal amplification by reversible exchange (SABRE). Chem A Eur J 25:7659-7668

23. Iali W, Roy SS, Tickner BJ, Ahwal F, Kennerley AJ, Duckett SB (2019) Hyperpolarising pyruvate through signal amplification by reversible exchange (SABRE). Angew Chem Int Ed 58:10271-10275

24. Rayner PJ, Duckett SB (2018) Signal amplification by reversible exchange (SABRE): from discovery to diagnosis. Angew Chem Int Ed 57:6742-6753

25. Aguilar JA, Elliott PIP, López-Serrano J, Adams RW, Duckett SB (2007) Only para-hydrogen spectroscopy (OPSY), a technique for the selective observation of para-hydrogen enhanced NMR signals. Chem Commun 11:1183-1185

26. Pileio G, Carravetta M, Levitt MH (2010) Storage of nuclear magnetization as long-lived singlet order in low magnetic field. Proc Natl Acad Sci 107:17135-17139

27. Carravetta M, Levitt MH (2004) Long-lived nuclear spin states in high-field solution NMR. J Am Chem Soc 126:6228-6229

28. Carravetta M, Levitt MH (2005) Theory of long-lived nuclear spin states in solution nuclear magnetic resonance. I. Singlet states in low magnetic field. J Chem Phys 122:1-14

29. Zhang Y, Basu K, Canary JW, Jerschow A (2015) Singlet lifetime measurements in an all-proton chemically equivalent spin system by hyperpolarization and weak spin lock transfers. Phys Chem Chem Phys 17:24370-24375

30. Theis T, Ortiz GX, Logan AWJ, Claytor KE, Feng Y, Huhn WP, Blum V, Malcolmson SJ, Chekmenev EY, Wang Q, Warren WS (2016) Direct and cost-efficient hyperpolarization of long-lived nuclear spin states on universal 15N2-diazirine molecular tags. Sci Adv 2:e1501438-e1501438

31. Cavallari E, Carrera C, Reineri F (2017) ParaHydrogen hyperpolarized substrates for molecular imaging studies. Isr J Chem 57:833-842

32. Reineri F, Boi T, Aime S (2015) ParaHydrogen induced polarization of ${ }^{13} \mathrm{C}$ carboxylate resonance in acetate and pyruvate. Nat Commun 6:5858

33. Iali W, Rayner PJ, Duckett SB (2018) Using parahydrogen to hyperpolarize amines, amides, carboxylic acids, alcohols, phosphates, and carbonates. Sci Adv 4:1-7

34. Gemeinhardt ME, Limbach MN, Gebhardt TR, Eriksson CW, Eriksson SL, Lindale JR, Goodson EA, Warren WS, Chekmenev EY, Goodson BM (2020) "Direct" ${ }^{13} \mathrm{C}$ hyperpolarization of ${ }^{13} \mathrm{C}$-acetate by microtesla NMR signal amplification by reversible exchange (SABRE). Angew Chem Int Ed 59:418-423

35. Korchak S, Mamone S, Glçggler S (2018) Over $50 \%{ }^{1} \mathrm{H}$ and ${ }^{13} \mathrm{C}$ polarization for generating hyperpolarized metabolites-a parahydrogen approach. Chem Open 7:672-676 
36. Korchak S, Yang S, Mamone S, Glçggler S (2018) Pulsed magnetic resonance to signal-enhance metabolites within seconds by utilizing para -hydrogen. Chem Open 5:344-348

37. Eills J, Cavallari E, Carrera C, Budker D, Aime S, Reineri F (2019) Real-time nuclear magnetic resonance detection of fumarase activity using parahydrogen-hyperpolarized $\left[1-{ }^{13} \mathrm{C}\right]$ fumarate. J Am Chem Soc 141:20209-20214

38. Cavallari E, Carrera C, Aime S, Reineri F (2017) ${ }^{13} \mathrm{C}$ MR hyperpolarization of lactate by using parahydrogen and metabolic transformation in vitro. Chem A Eur J. https://doi.org/10.1002/ chem.201605329

39. Coffey AM, Shchepin RV, Truong ML, Wilkens K, Pham W, Chekmenev EY (2016) Open-source automated parahydrogen hyperpolarizer for molecular imaging using ${ }^{13} \mathrm{C}$ metabolic contrast agents. Anal Chem 88:8279-8288

40. Shchepin RV, Coffey AM, Waddell KW, Chekmenev EY (2014) Parahydrogen induced polarization of $1-{ }^{13} \mathrm{C}$-phospholactate- $\mathrm{d}$ 2 for biomedical imaging with $>30,000,000$-fold NMR signal enhancement in water. Anal Chem 86:5601-5605

41. Cavallari E, Carrera C, Sorge M, Bonne G, Muchir A, AimeSilvio RF (2018) The ${ }^{13} \mathrm{C}$ hyperpolarized pyruvate generated by parahydrogen detects the response of the heart to altered metabolism in real time. Sci Rep 8:1-9

42. Cavallari E, Carrera C, Aime S, Reineri F (2018) Studies to enhance the hyperpolarization level in PHIP-SAH-produced C13-pyruvate. J Magn Reson 289:12-17

43. Tickner BJ, Semenova O, Iali W, Rayner PJ, Whitwood AC, Duckett SB (2020) Optimisation of pyruvate hyperpolarisation using SABRE by tuning the active magnetisation transfer catalyst. Catal Sci Technol 10:1343-1355

44. Berner S, Schmidt AB, Zimmermann M, Pravdivtsev AN, Glöggler S, Hennig J, von Elverfeldt D, Hövener JB (2019) SAMBADENA hyperpolarization of 13C-succinate in an MRI: singlet-triplet mixing causes polarization loss. ChemistryOpen 8:728-736

45. Kaltschnee L, Jagtap AP, McCormick J, Wagner S, Bouchard LS, Utz M, Griesinger C, Glöggler S (2019) Hyperpolarization of amino acids in water utilizing parahydrogen on a rhodium nanocatalyst. Chem A Eur J 25:11031-11035

46. Soon PC, Xu X, Zhang B, Gruppi F, Canary JW, Jerschow A (2013) Hyperpolarization of amino acid precursors to neurotransmitters with parahydrogen induced polarization. Chem Commun 49:5304-5306

47. Glöggler S, Wagner S, Bouchard L-S (2015) Hyperpolarization of amino acid derivatives in water for biological applications. Chem Sci 6:4261-4266

48. Glöggler S, Müller R, Colell J, Emondts M, Dabrowski M, Blümich B, Appelt S (2011) Para-hydrogen induced polarization of amino acids, peptides and deuterium-hydrogen gas. Phys Chem Chem Phys 13:13759-13764

49. Colell JFP, Logan AWJ, Zhou Z, Shchepin RV, Barskiy DA, Ortiz GX, Wang Q, Malcolmson SJ, Chekmenev EY, Warren WS, Theis T (2017) Generalizing, extending, and maximizing nitrogen- 15 hyperpolarization induced by parahydrogen in reversible exchange. J Phys Chem C 121:6626-6634

50. Richardson PM, Iali W, Roy SS, Rayner PJ, Halse ME, Duckett SB (2019) Rapid ${ }^{13} \mathrm{C}$ NMR hyperpolarization delivered from: para-hydrogen enables the low concentration detection and quantification of sugars. Chem Sci 10:10607-10619

51. Olaru AM, Burns MJ, Green GGR, Duckett SB (2017) SABRE hyperpolarisation of vitamin $\mathrm{B} 3$ as a function of $\mathrm{pH}$. Chem Sci 8:2257-2266

52. Zeng H, Xu J, Gillen J, McMahon MT, Artemov D, Tyburn JM, Lohman JAB, Mewis RE, Atkinson KD, Green GGR, Duckett SB, Van Zijl PCM (2013) Optimization of SABRE for polarization of the tuberculosis drugs pyrazinamide and isoniazid. J Magn Reson 237:73-78

53. Kidd BE, Gesiorski JL, Gemeinhardt ME, Shchepin RV, Kovtunov KV, Koptyug IV, Chekmenev EY, Goodson BM (2018) Facile removal of homogeneous SABRE catalysts for purifying hyperpolarized metronidazole, a potential hypoxia sensor. J Phys Chem C 122:16848-16852

54. Braun M, Häseli S, Rösch F, Piel M, Münnemann K (2018) NMR Hyperpolarization of established PET tracers. ChemistrySelect 3:5176-5184

55. Cunningham CH, Lau JYC, Chen AP, Geraghty BJ, Perks WJ, Roifman I, Wright GA, Connelly KA (2016) Hyperpolarized ${ }^{13} \mathrm{C}$ metabolic MRI of the human heart initial experience. Circ Res 119:1177-1182

56. Gallagher FA, Woitek R, McLean MA, Gill AB, Garcia RM, Provenzano E, Riemer F, Kaggie J, Chhabra A, Ursprung S, Grist JT, Daniels CJ, Zaccagna F, Laurent MC, Locke M, Hilborne S, Frary A, Torheim T, Boursnell C, Schiller A, Patterson I, Slough R, Carmo B, Kane J, Biggs H, Harrison E, Deen SS, Patterson A, Lanz T, Kingsbury Z, Ross M, Basu B, Baird R, Lomas DJ, Sala E, Wason J, Rueda OM, Chin SF, Wilkinson IB, Graves MJ, Abraham JE, Gilbert FJ, Caldas C, Brindle KM (2020) Imaging breast cancer using hyperpolarized carbon-13 MRI. Proc Natl Acad Sci U S A 117:2092-2098

57. Nelson SJ, Kurhanewicz J, Vigneron DB, Larson PEZ, Harzstark AL, Ferrone M, Van CM, Chang JW, Bok R, Park I, Reed G, Carvajal L, Small EJ, Munster P, Weinberg VK, Ardenkjaerlarsen JH, Chen AP, Hurd RE, Odegardstuen L, Robb FJ, Tropp J, Murray JA (2013) Metabolic imaging of patients with prostate cancer using hyperpolarized [1-13C]pyruvate. Sci Transl Med 5:198108

58. Miloushev VZ, Granlund KL, Boltyanskiy R, Lyashchenko SK, Deangelis LM, Mellinghoff IK, Brennan CW, Tabar V, Yang TJ, Holodny AI, Sosa RE, Guo YW, Chen AP, Tropp J, Robb F, Keshari KR (2018) Metabolic imaging of the human brain with $\mathrm{C}$ lactate production in brain tumor patients. Cancer Res 78:3755-3761

59. Chen AP, Kurhanewicz J, Bok R, Xu D, Joun D, Zhang V, Nelson SJ, Hurd RE, Vigneron DB (2008) Feasibility of using hyperpolarized $\left[1-{ }^{13} \mathrm{C}\right]$ lactate as a substrate for in vivo metabolic ${ }^{13} \mathrm{C}$ MRSI studies. Magn Reson Imaging 26:721-726

60. Kennedy BWC, Kettunen MI, Hu D, Brindle KM (2012) Probing lactate dehydrogenase activity in tumors by measuring hydrogen/ deuterium exchange in hyperpolarized $\mathrm{L}-\left[1-{ }^{13} \mathrm{C}, \mathrm{U}-2 \mathrm{H}\right]$ lactate. J Am Chem Soc 134:4969-4977

61. Bastiaansen JAM, Cheng T, Mishkovsky M, Duarte JMN, Comment A, Gruetter R (2013) In vivo enzymatic activity of acetylCoA synthetase in skeletal muscle revealed by ${ }^{13} \mathrm{C}$ turnover from hyperpolarized $\left[1-{ }^{13} \mathrm{C}\right]$ acetate to $\left[1-{ }^{13} \mathrm{C}\right]$ acetylcarnitine. Biochim Biophys Acta - Gen Subj 1830:4171-4178

62. Cavallari E, Carrera C, Boi T, Aime S, Reineri F (2015) Effects of magnetic field cycle on the polarization transfer from parahydrogen to heteronuclei through long-range J-couplings. J Phys Chem B 119:10035-10041

63. Shchepin RV, Barskiy DA, Coffey AM, Manzanera Esteve IV, Chekmenev EY (2016) Efficient synthesis of molecular precursors for para-hydrogen-induced polarization of ethyl acetate$1-{ }^{13} \mathrm{C}$ and beyond. Angew Chem Int Ed 55:6071-6074

64. Cavallari E, Carrera C, Aime S, Reineri F (2017) C-MR hyperpolarization of lactate using parahydrogen and metabolic transformation in vitro. Chem A Eur J 23:1200-1204

65. Cavallari E, Carrera C, Aime S, Reineri F (2019) Metabolic studies of tumor cells using $\left[1-{ }^{13} \mathrm{C}\right]$ pyruvate hyperpolarized by means of PHIP-side arm hydrogenation. Chem Phys Chem $20: 318-325$ 
66. Cavallari E, Carrera C, Di Matteo G, Bondar O, Aime S, Reineri F (2020) In-vitro NMR studies of prostate tumor cell metabolism by means of hyperpolarized $\left[1-{ }^{13} \mathrm{C}\right]$ pyruvate obtained using the PHIP-SAH method. Front Oncol 10:1-9

67. Cavallari E, Carrera C, Sorge M, Bonne G, Muchir A, Aime S, Reineri F (2018) The ${ }^{13} \mathrm{C}$ hyperpolarized pyruvate generated by PARAHYDROGEN detects the response of the heart to altered metabolism in real time. Sci Rep 8:8366

68. Gallagher FA, Kettunen MI, Hu D-E, Jensen PR, Zandt RI, Karlsson M, Gisselsson A, Nelson SK, Witney TH, Bohndiek SE, Hansson G, Peitersen T, Lerche MH, Brindle KM (2009) Production of hyperpolarized $\left[1,4-{ }^{13} \mathrm{C} 2\right]$ malate from $\left[1,4-{ }^{13} \mathrm{C} 2\right]$ fumarate is a marker of cell necrosis and treatment response in tumors. PNAS 106:19801-19806

69. Clatworthy MR, Kettunen MI, Hu DE, Mathews RJ, Witney TH, Kennedy BWC, Bohndiek SE, Gallagher FA, Jarvis LB, Smith KGC, Brindle KM (2012) Magnetic resonance imaging with hyperpolarized $\left[1,4-{ }^{13} \mathrm{C} 2\right]$ fumarate allows detection of early renal acute tubular necrosis. Proc Natl Acad Sci U S A 109:13374-13379

70. Ripka B, Eills J, Kour H, Leutzsch M, Levitt MH, Munnemann K (2018) Hyperpolarized fumarate via parahydrogen. Chem Comm 54:12246-12249

71. Schleyer D, Niessen HG, Bargon J (2001) In situ ${ }^{1}$ H-PHIP-NMR studies of the stereoselective hydrogenation of alkynes to (E)alkenes catalyzed by a homogeneous $[\mathrm{Cp} * \mathrm{Ru}]+$ catalyst. New J Chem 25:423-426

72. Guthertz A, Leutzsch M, Wolf LM, Gupta P, Rummelt SM, Goddard R, Farès C, Thiel W, Fürstner A (2018) Half-sandwich ruthenium carbene complexes link trans-hydrogenation and gem-hydrogenation of internal alkynes. J Am Chem Soc 140:3156-3169

73. Stevanato G, Eills J, Bengs C, Pileio G (2017) A pulse sequence for singlet to heteronuclear magnetization transfer : S-spin I-spins I-spins $\tau \tau \tau \tau$ S-spin $\tau \tau$. J Magn Reson 277:169-178

74. Eills J, Alonso-Valdesueiro J, Salazar Marcano DE, Ferreira da Silva J, Alom S, Rees GJ, Hanna JV, Carravetta M, Levitt MH (2018) Preservation of nuclear spin order by precipitation. ChemPhysChem 19:40-44

75. Jóhannesson H, Axelsson O, Karlsson M (2004) Transfer of para-hydrogen spin order into polarization by diabatic field cycling. Comptes Rendus Phys 5:315-324

76. Goldman M, Jóhannesson H (2005) Conversion of a proton pair para order into $\mathrm{C}-13$ polarization by $\mathrm{rf}$ irradiation, for use in MRI. Comptes Rendus Phys 6:575-581

77. Eills J, Blanchard JW, Wu T, Bengs C, Hollenbach J, Budker D, Levitt MH (2019) Polarization transfer via field sweeping in parahydrogen-enhanced nuclear magnetic resonance. J Chem Phys doi 10(1063/1):5089486

78. Bhattacharya P, Chekmenev EY, Perman WH, Harris KC, Lin AP, Norton VA, Tan CT, Ross BD, Weitekamp DP (2007) Towards hyperpolarized ${ }^{13} \mathrm{C}$-succinate imaging of brain cancer. J Magn Reson 186:150-155

79. Chekmenev EY, Hövener J, Norton VA, Harris K, Batchelder LS, Bhattacharya P, Ross BD, Weitekamp DP (2008) PASADENA hyperpolarization of succinic acid for MRI and NMR spectroscopy. J Am Chem Soc 130:4212-4213

80. Bär S, Lange T, Leibfritz D, Hennig J, Von ED, Hövener JB (2012) On the spin order transfer from parahydrogen to another nucleus. J Magn Reson 225:25-35

81. Coffey AM, Kovtunov KV, Barskiy DA, Koptyug IV, Shchepin RV, Waddell KW, He P, Groome KA, Best QA, Shi F, Goodson BM, Chekmenev EY (2014) High-resolution low-field molecular magnetic resonance imaging of hyperpolarized liquids. Anal Chem 86:9042-9049
82. Hövener J-B, Chekmenev EY, Harris KC, Perman WH, Tran TT, Ross BD, Bhattacharya P (2009) Quality assurance of PASADENA hyperpolarization for carbon-13 biomolecules. Magn Reson Mater Phy 22:123-134

83. Hövener JB, Chekmenev EY, Harris KC, Perman WH, Robertson LW, Ross BD, Bhattacharya P (2009) PASADENA hyperpolarization of $13 \mathrm{C}$ biomolecules: equipment design and installation. Magn Reson Mater Phy 22:111-121

84. Reineri F, Viale A, Ellena S, Boi T, Daniele V, Gobetto R, Aime S (2011) Use of labile precursors for the generation of hyperpolarized molecules from hydrogenation with parahydrogen and aqueous-phase extraction. Angew Chemie - Int Ed 50:7350-7353

85. Coffey AM, Feldman MA, Shchepin RV, Barskiy DA, Truong ML, Pham W, Chekmenev EY (2017) High-resolution hyperpolarized in vivo metabolic ${ }^{13} \mathrm{C}$ spectroscopy at low magnetic field $(48.7 \mathrm{mT})$ following murine tail-vein injection. J Magn Reson 281:246-252

86. Wigh Lipsø K, Hansen ESS, Tougaard RS, Laustsen C, Ardenkjær-Larsen JH (2017) Renal MR angiography and perfusion in the pig using hyperpolarized water. Magn Reson Med 78:1131-1135

87. Von Morze C, Larson PEZ, Hu S, Yoshihara HAI, Bok RA, Goga A, Ardenkjaer-Larsen JH, Vigneron DB (2012) Investigating tumor perfusion and metabolism using multiple hyperpolarized ${ }^{13} \mathrm{C}$ compounds: HP001, pyruvate and urea. Magn Reson Imaging 30:305-311

88. Grant AK, Vinogradov E, Wang X, Lenkinski RE, Alsop DC (2011) Perfusion imaging with a freely diffusible hyperpolarized contrast agent. Magn Reson Med 66:746-755

89. Pinon AC, Capozzi A, Ardenkjær-Larsen JH (2020) Hyperpolarized water through dissolution dynamic nuclear polarization with UV-generated radicals. Commun Chem 3:1-9

90. Malayeri AA, Brooks KM, Bryant LH, Evers R, Kumar P, Reich DS, Bluemke DA (2016) National Institutes of Health Perspective on Reports of gadolinium deposition in the brain. J Am Coll Radiol 13:237-241

91. Shchepin RV, Coffey AM, Waddell KW, Chekmenev EY (2012) PASADENA hyperpolarized 13C phospholactate. J Am Chem Soc 134:3957-3960

92. Salnikov OG, Shchepin RV, Chukanov NV, Jaigirdar L, Pham W, Kovtunov KV, Koptyug IV, Chekmenev EY (2018) Effects of deuteration of ${ }^{13} \mathrm{C}$-enriched phospholactate on efficiency of parahydrogen-induced polarization by magnetic field cycling. $\mathrm{J}$ Phys Chem C 122:24740-24749

93. Shchepin RV, Pham W, Chekmenev EY (2014) Dephosphorylation and biodistribution of $1-{ }^{13} \mathrm{C}$-phospholactate in vivo. J Label Compd Radiopharm 57:517-524

94. Bastiaansen JAM, Schwitter J, Gruetter R (2018) Probing cardiac metabolism by hyperpolarized ${ }^{13} \mathrm{C}$ MR using an exclusively endogenous substrate mixture and photo-induced nonpersistent radicals. Magn Reson Med 79:2451-2459

95. Cunningham CH, Lau JYC, Chen AP, Geraghty BJ, Perks WJ, Roifman I, Wright GA, Connelly KA (2016) Hyperpolarized ${ }^{13} \mathrm{C}$ metabolic MRI of the human heart: initial experience. Circ Res 119:1177-1182

96. Day SE, Kettunen MI, Gallagher FA, Hu D-E, Lerche M, Wolber J, Golman K, Ardenkjaer-Larsen JH, Brindle KM (2007) Detecting tumor response to treatment using hyperpolarized ${ }^{13} \mathrm{C}$ magnetic resonance imaging and spectroscopy. Nat Med 13:1382-1387

97. Natterer J, Bargon J (1997) Parahydrogen induced polarization. Prog Nucl Magn Reson Spectrosc 31:293-315

98. Canet D, Aroulanda C, Mutzenhardt P, Aime S, Gobetto R, Reineri F (2006) Para-hydrogen enrichment and hyperpolarization. Concepts Magn Reson Part A Bridg Educ Res 28:321-330 
99. Feng B, Coffey AM, Colon RD, Chekmenev EY, Waddell KW (2012) A pulsed injection parahydrogen generator and techniques for quantifying enrichment. J Magn Reson 214:258-262

100. Hövener JB, Bär S, Leupold J, Jenne K, Leibfritz D, Hennig J, Duckett SB, Von Elverfeldt D (2013) A continuous-flow, highthroughput, high-pressure parahydrogen converter for hyperpolarization in a clinical setting. NMR Biomed 26:124-131

101. Reineri F, Viale A, Dastrù W, Gobetto R, Aime S (2011) How to design 13C para-hydrogen-induced polarization experiments for MRI applications. Contrast Media Mol Imaging 6:77-84

102. Pravica MG, Weitekamp DP (1988) Net Nmr alignment by adiabatic transport of para-hydrogen addition-products to high magnetic-field. Chem Phys Lett 145:255-258

103. Stephan M, Kohlmann O, Niessen HG, Eichhorn A, Bargon J (2002) 13C PHIP NMR spectra and polarization transfer during the homogeneous hydrogenation of alkynes with parahydrogen. Magn Reson Chem 40:157-160

104. Natterer J, Schedletzky O, Barkemeyer J, Bargon J, Glaser S (1998) Investigating catalytic processes with parahydrogen: evolution of zero-quantum coherence in AA'X spin systems. J Magn Reson 133:92-97

105. Pravdivtsev AN, Yurkovskaya AV, Lukzen NN, Ivanov KL, Vieth HM (2014) Highly efficient polarization of Spin-1/2 insensitive NMR nuclei by adiabatic passage through level anticrossings. J Phys Chem Lett 5:3421-3426

106. Haake M, Natterer J, Bargon J (1996) Efficient NMR pulse sequences to transfer the parahydrogen-induced polarization to hetero nuclei. J Am Chem Soc 118:8688-8691

107. Goldman M, Johannesson H, Axelsson O, Karlsson M (2006) Design and implementation of ${ }^{13} \mathrm{C}$ hyper polarization from parahydrogen, for new MRI contrast agents. Comptes Rendus Chim 9:357-363

108. Kadlecek S, Emami K, Ishii M, Rizi R (2010) Optimal transfer of spin-order between a singlet nuclear pair and a heteronucleus. J Magn Reson 205:9-13

109. Devience SJ, Walsworth RL, Rosen MS (2013) Preparation of nuclear spin singlet states using spin-lock induced crossing. Phys Rev Lett 111:1-5

110. Eills J, Stevanato G, Bengs C, Glöggler S, Elliott SJ, Alonsovaldesueiro J, Pileio G, Levitt MH (2017) Singlet order conversion and parahydrogen-induced hyperpolarization of ${ }^{13} \mathrm{C}$ nuclei in near-equivalent spin systems. J Magn Reson 274:163-172

111. Cavallari E, Carrera C, Aime S, Reineri F (2018) Studies to enhance the hyperpolarization level in PHIP-SAH-produced. J Magn Reson 289:12-17

112. Emondts M, Colell JFP, Blümich B, Schleker PPM (2017) Polarization transfer efficiency in PHIP experiments. Phys Chem Chem Phys 19:21933-21937

113. Schmidt AB, Berner S, Schimpf W, Müller C, Lickert T, Schwaderlapp N, Knecht S, Skinner JG, Dost A, Rovedo P, Hennig J, von Elverfeldt D, Hövener J-B (2017) Liquid-state carbon-13 hyperpolarization generated in an MRI system for fast imaging. Nat Commun 8:14535

114. Giernoth R, Huebler P, Bargon J (1998) Intermediate productcatalyst complexes in the homogeneous hydrogenation of styrene derivatives with parahydrogen and cationic $\mathrm{Rh}(\mathrm{I})$ catalysts. Angew Chem Int Ed 37:2473-2475

115. Giernoth R, Heinrich H, Adams NJ, Deeth RJ, Bargon J, Brown JM (2000) PHIP detection of a transient rhodium dihydride intermediate in the homogeneous hydrogenation of dehydroamino acids. J Am Chem Soc 122:12381-12382

116. Itoda M, Naganawa Y (2019) Structural exploration of rhodium catalysts and their kinetic studies for e ffi cient parahydrogeninduced polarization by side arm hydrogenation. RSC Adv 9:18183-18190
117. Chan H, Bhattacharya P, Imam A, Freundlich A, Tran T, Perman W, Lin A, Harris K, Chekmenev E, Ingram M, Ross B (2009) No clinical toxicity is seen in vivo from hyperpolarized PASADENA MR reagents or catalyst. In: Proc 17th Sci Meet Int Soc Magn Reson Med Honolulu, p 2448

118. Barskiy DA, Ke LA, Li X, Stevenson V, Widarman N, Zhang H, Truxal A, Pines A (2018) Rapid catalyst capture enables metalfree para-hydrogen-based hyperpolarized contrast agents. J Phys Chem Lett 9:2721-2724

119. Eills J, Alonso-valdesueiro J, Marcano ES, Ferreira J, Alom S, Rees GJ, Hanna JV, Carravetta M, Levitt MH (2018) Preservation of nuclear spin order by precipitation. Chem Phys Chem 19:40-44

120. Koptyug IV, Kovtunov KV, Burt SR, Anwar MS, Hilty C, Han S-I, Pines A, Sagdeev RZ (2007) Para-hydrogen-induced polarization in heterogeneous hydrogenation reactions. J Am Chem Soc 129:5580-5586

121. Kovtunov KV, Beck IE, Bukhtiyarov VI, Koptyug IV (2008) Observation of parahydrogen-induced polarization in heterogeneous hydrogenation on supported metal catalysts. Angew Chem Int Ed 47:1492-1495

122. Koptyug IV, Zhivonitko VV, Kovtunov KV (2010) New perspectives for parahydrogen-induced polarization in liquid phase heterogeneous hydrogenation: an aqueous phase and ALTADENA study. ChemPhysChem 11:3086-3088

123. Salnikov OG, Kovtunov KV, Koptyug IV (2015) Production of catalyst-free hyperpolarised ethanol aqueous solution via heterogeneous hydrogenation with parahydrogen. Sci Rep 5:13930

124. Kovtunov KV, Barskiy DA, Salnikov OG, Shchepin RV, Coffey AM, Kovtunova LM, Bukhtiyarov VI, Koptyug IV, Chekmenev EY (2016) Toward production of pure ${ }^{13} \mathrm{C}$ hyperpolarized metabolites using heterogeneous parahydrogen-induced polarization of ethyl[1- ${ }^{13}$ C $]$ acetate. RSC Adv 6:69728-69732

125. Kovtunov KV, Barskiy DA, Shchepin RV, Salnikov OG, Prosvirin IP, Bukhtiyarov AV, Kovtunova LM, Bukhtiyarov VI, Koptyug IV, Chekmenev EY (2016) Production of pure aqueous ${ }^{13} \mathrm{C}$-hyperpolarized acetate by heterogeneous parahydrogeninduced polarization. Chem A Eur J 630090:16446-16449

126. Bales LB, Kovtunov KV, Barskiy DA, Shchepin RV, Co AM, Kovtunova LM, Bukhtiyarov AV, Feldman MA, Bukhtiyarov VI, Chekmenev EY, Koptyug IV, Goodson BM (2017) Aqueous, heterogeneous para-hydrogen-induced $15 \mathrm{~N}$ polarization. J Phys Chem 121:7-12

127. McCormick J, Korchak S, Mamone S, Ertas YN, Liu Z, Verlinsky L, Wagner S, Glöggler S, Bouchard L (2018) More than $12 \%$ polarization and 20 minute lifetime of $15 \mathrm{~N}$ in a choline derivative utilizing parahydrogen and a rhodium nanocatalyst in water. Angew Chem 130:10852-10856

128. Zhao EW, Maligal-Ganesh R, Xiao C, Goh TW, Qi Z, Pei Y, Hagelin-Weaver HE, Huang W, Bowers CR (2017) Silica-encapsulated Pt-Sn intermetallic nanoparticles: a robust catalytic platform for parahydrogen-induced polarization of gases and liquids. Angew Chem Int Ed 56:3925-3929

129. Cai C, Coffey AM, Shchepin RV, Chekmenev EY, Waddell KW (2013) Efficient transformation of parahydrogen spin order into heteronuclear magnetization. J Phys Chem B 117:1219-1224

130. Kadlecek S, Vahdat V, Nakayama T, Ng D, Emami K, Rizi R (2011) A simple and low-cost device for generating hyperpolarized contrast agents using parahydrogen. NMR Biomed 24:933-942

131. Waddell KW, Coffey AM, Chekmenev EY (2011) In situ detection of PHIP at $48 \mathrm{mT}$ : demonstration using a centrally controlled polarizer. J Am Chem Soc 133:153-157

132. Schmidt AB, Berner S, Braig M, Zimmermann M, Hennig J, Von Elverfeldt D, Hövener JB (2018) In vivo 13C-MRI using SAMBADENA. PLOS ONE 13:1-15 
133. Kiryutin AS, Sauer G, Hadjiali S, Yurkovskaya AV, Breitzke H, Buntkowsky G (2017) A highly versatile automatized setup for quantitative measurements of PHIP enhancements. J Magn Reson 285:26-36

134. Salnikov OG, Chukanov NV, Shchepin RV, Manzanera Esteve IV, Kovtunov KV, Koptyug IV, Chekmenev EY (2019) Parahydrogen-induced polarization of $1-{ }^{13} \mathrm{C}$-acetates and $1-{ }^{13} \mathrm{C}$-pyruvates using sidearm hydrogenation of vinyl, allyl, and propargyl esters. J Phys Chem C 123:12827-12840

Publisher's Note Springer Nature remains neutral with regard to jurisdictional claims in published maps and institutional affiliations. 